[REVIEW ARTICLE]

\title{
UTTERING AND INTERPRETING TREES
}

\author{
YOSHIHISA KITAGAWA \\ Indiana University
}

Uttering Trees, by Norvin Richards, MIT Press, Cambridge, MA, 2010, x+ $233 \mathrm{pp}$.

This article first selectively overviews the discussion on the interaction of phonology and syntax offered in Richards (2010), then pursues the same project from a different angle. Pointing out that both $w$ h-in-situ and overt wh-movement express sound-meaning correlations by appealing to some physical marking at surface level, we propose that both should be regarded as instances of overt syntax. Accordingly, the notion 'overt syntax' is redefined as the grammatical procedure that synchronizes PF- and LF-effects. We then argue that the synchronized PF-LF effects of overt syntax can be captured if feature complexes that induce the legibility of linguistic expressions at PF and at LF are encoded into lexical items.*

Keywords: Wh-questions, prosody, Wh-movement, Wh-in-situ, PF-LF synchronization, legibility

\section{Introduction}

Syntacticians have long known that the acceptability and interpretation of a sentence depends on the prosodic pattern assigned to it. Such observations, however, have often been made only in passing, left behind as unsolved mysteries or as matters irrelevant to grammar, typically mentioned in footnotes. Even when consistent correlations between prosody and semantic interpretation are discovered, they are often presented merely as descriptive observations without elucidating how the grammar makes such correla-

* I am grateful to Aaron Albin, Julie Auger, Muamera Begovic, Isabelle Darcy, Laurent Dekydtspotter, Leslie Gabriele, Norbert Hornstein, Yuyin Hsu, Marija Jankovic, Miguel Rodriguez-Mondoñedo, Seth Wood and two anonymous reviewers for invaluable comments, discussion and/or judgments. An unabridged version of this article can be downloaded from http://www.iub.edu/ ykling/HTML\%20files/Publications.html. 
tions possible, let alone addressing what the exact role of syntax is. In this regard, Norvin Richards' recent monograph Uttering Trees (Richards (2010)) is a rare and innovative piece of work. It attempts to substantiate the view that some of properties of syntax are determined by its interface with phonology. In Section 2 of this article, we first provide a selective overview of this monograph. Then in Section 3, we explore an approach distinct from the one proposed and argued for in the monograph, concentrating our discussion on the materials presented in Chapter 3 of the book.

\section{Richards on Pronunciation and Syntax}

The two main chapters of Richards (2010), Chapter 2 and Chapter 3, both discuss the relation between pronunciation and syntax. Beyond this general commonality, however, they are largely distinct and independent chapters and there is little connection between the two. Below, we overview the two chapters one by one, starting with Chapter 2 .

\subsection{Distinctness in Linearization}

This chapter first advocates the view that grammar universally demands two linguistic expressions to be different when they are pronounced in sequence, then attempts to find out how exactly such a constraint should be formalized. The investigation starts with multiple ellipsis remnants in English as in (1) and (2) below (Richards' (6) and (7) with his acceptability judgments indicated).

(1) a. *Every man admired every woman, except [DP John] [DP Mary]

b. *I know everyone insulted someone, but I don't know [DP who] [DP whom]

(2) a. Every man danced with every woman, except [DP John] [PP with Mary]

b. I know everyone danced with someone, but I don't know [DP who] [pp with whom]

Richards claims that the contrast here follows from the formal constraint being proposed, which bans two remnant DPs from being pronounced in sequence in $(1 \mathrm{a}, \mathrm{b})$. On the other hand, no such violation arises in $(2 \mathrm{a}, \mathrm{b})$ since the ellipsis-remnants are of two distinct types (DP and PP).

The proposal made in this chapter involves the background assumptions as listed in (3).

(3) a. The linear order of syntactic nodes and lexical items is de- 
termined when Spell-Out applies in accordance with the Linear Correspondence Axiom.

Linear Correspondence Axiom (LCA: Kayne (1994: 33))

Let $\mathrm{X}, \mathrm{Y}$ be nonterminals and $\mathrm{x}, \mathrm{y}$ terminals such that $\mathrm{X}$ dominates $\mathrm{x}$ and $\mathrm{Y}$ dominates $\mathrm{y}$.

Then if $\mathrm{X}$ asymmetrically c-commands $\mathrm{Y}$, $\mathrm{x}$ precedes $\mathrm{y}$.

b. Spell-Out applies cyclically each time a strong phase is created. Strong phases include CP, transitive (not intransitive) vP, PP and KP (Chomsky (2000), Chomsky (2001)).

c. Lexical heads are merged through 'Early Insertion' as complete lexical items. In contrast, functional heads are merged without their phonological information. Their phonological information is introduced post-syntactically by 'Late Insertion,' as argued for in Distributed Morphology (Halle and Marantz (1993), Embick and Noyer (2001), et al.).

d. Linearization is ordered before Late Insertion, hence the phonological features of functional heads have no effect on linearization. Linearization treats overt and covert functional heads on par.

Within this framework, the constraint in (4) is proposed to be a formal condition imposed on linearization.

(4) Distinctness (Richards' (5))

If a linearization statement $\langle\alpha, \alpha\rangle$ is generated, the derivation crashes.

This condition rejects trees in which two nodes of type $\alpha$ are to be linearized in the same "Spell-Out domain," defined as the complement (and, hence, the sister) of the phase head (Nissenbaum (2000)). It is also claimed that what counts as distinct types of $\alpha$ in (4) may vary cross-linguistically. For instance, Richards argues that this is defined by syntactic category in English, by case in Japanese, and by properties like gender and animacy in other languages.

With this proposal, Richards examines various phenomena that, at first glance, do not appear to have anything to do with the notion 'distinctness.' He invites the reader, often in an amusing way, to analyze these phenomena in accordance with the insightful mechanisms offered by his approach. He also makes maximal use of his rich knowledge of typologically diverse languages in the pursuit of this project. The diversity of languages and empirical phenomena covered in this chapter is quite impressive, and the analyses and generalizations offered therein are highly enlightening. The 
work presents itself as an exemplary research project based on an innovative idea pursued under a tightly-knit formal system of grammar.

Since an attempt to discuss all of the topics and empirical phenomena covered in this chapter would be too reckless, I will only point out in this section some apparent misanalyses of the data and theoretical concerns that arise in the proposed approach, concentrating on the languages that permit me to offer reasonably detailed and deliberate analyses.

First, the impressive diversity of empirical coverage in this monograph in itself might actually have produced the adverse effect of overextending the limits of his analysis. More specifically, some of the empirical phenomena claimed to involve Distinctness violations may in fact not involve such violations at all. For instance, the contrast between (5a) and (5b) below (Richards' $(89 a, b))$ is presented as supporting evidence that the Distinctness effect is sensitive to case in Japanese.

(5) a. [Sensee-o hihansita] gakusee-ga koko-ni oozee iru-kedo, teacher-Acc criticized student-Nom here-at many exist-but dare-ga dare-o-ka oboeteinai who-Nom who-Acc-Comp wh remember-Neg (literally) 'There are lots of students here who criticized teachers, but I don't remember who who.'

b. *[Sensee-ga sukina] gakusee-ga koko-ni oozee iru-kedo, teacher-Nom like student-Nom here-at many exist-but dare-ga dare-ga-ka oboeteinai who-Nom who-Nom-Comp Wh $_{\text {remember-Neg }}$ (literally) 'There are lots of students here who like teachers, but I don't remember who who.'

Richards reports that, while multiple sluicing in Japanese generally allows multiple DP remnants marked by distinct case particles, as in (5a), those marked by the same case, as in (5b), are not permitted. He also reports that acceptability judgments are significantly improved in sentences involving identical case marking but a difference in animacy, as in (6) below, implying that an animacy feature may also play a partial role in the definition of distinctness in Japanese.

(6) [Doobutu-ga sukina] hito-ga koko-ni oozee iru-kedo, animal-Nom like person-Nom here-at many exist-but dare-ga nani-ga-ka oboeteinai who-Nom what-Nom-Comp Wh $_{\text {remember-Neg }}$ (literally) 'There are lots of people here who like animals, but I don't remember who what.' 
However, the source of the awkwardness that arises in (5b) (at least in its first round of parsing) may be independent of a Distinctness violation. To begin with, (5b) is handicapped by involving a subject NP in the antecedent clause that is ambiguously analyzable, as indicated in $(7 \mathrm{a}, \mathrm{b})$.

$$
\begin{aligned}
& \text { a. [NP [TP Sensee-ga pro } \left.\left.{ }_{1} \text { sukina }\right] \text { gakusee }{ }_{1}\right] \\
& \text { teacher-Nom like student } \\
& \text { 'the student(s) whom the teacher(s) like(s)' } \\
& \text { b. [NP [ }\left[\begin{array}{lll}
\text { TP } \text { pro }_{1} & \text { Sensee-ga sukina } & \text { gakusee }_{1}
\end{array}\right. \\
& \text { teacher-Nom like student } \\
& \text { 'the student(s) who like(s) the teacher(s)' (= Intended inter- } \\
& \text { pretation in (5b)) }
\end{aligned}
$$

The antecedent clause in $(5 b)$ therefore makes it difficult for language users (i.e. listeners and readers) to determine how the multiple wh-questions fit into specific word order and indicate a 'sorting key' (Kuno (1982)). This troublesome situation is only made worse by the multiple remnants of whphrases with identical case marking. While the subject NP in (6) is ambiguous between 'people who like animals' and 'people whom animals like' and therefore has the same potential problem, the former is the more pragmatically (and discoursally) likely interpretation, with doobutu-ga 'animalNOM' analyzed as the object. More generally, this means that an animacy distinction within multiple remnants encourages the language user utilize pragmatic likelihood, thus making it easy to determine how the remnants fit into default word order in sentences like (6). In fact, if we reduce the likelihood of ambiguity in the subject NP of the antecedent clause, as in (8) below, greatly improved acceptability can be obtained, even though the multiple remnants have the same case and the same animacy.

(8) [Aidoru-kasyu-ga sukida-tteyuu] tiineezyaa-ga sonoba-ni nanninka idol-singer-Nom like-saying teenager-Nom there-at some itakedo, dono-ko-ga dono-kasyu-ga(-datta)-ka(-wa) existed-but which-kid-Nom which-singer-Nom-was-Comp ${ }_{W h}$-Top oboeteinai.

remember-Neg (literally) 'There were several teenagers there who said they love idol singers, but I don't remember which kid which singer.'

This result brings to question the relevance of Distinctness (defined in terms of case or animacy) to the acceptability difference in (5).

Next, responding to a reviewer's observation, Richards also concludes that "multiple clefts in Japanese are generally allowed, but not when the clefted phrases are DPs with the same case, as in (9b) (Richards' (92b))." (p. 45) 
(9) a. [Sukina-no]-wa Taroo-ga Hanako-o da

like-that.which-Top Taroo-Nom Hanako-Acc Cop

(literally) 'It is Taroo Hanako that likes.'
b.??[Sukina-no]-wa Taroo-ga Hanako-ga da
like-that.which-Top Taroo-Nom Hanako-Nom Cop
(literally) 'It is Taroo Hanako that likes.'

The same interpretive problems just pointed out for (5b) arise here again for (9b), perhaps even more gravely since neither subject nor object is overtly expressed in the antecedent clause ([pro pro sukina-no]). Moreover, multiple clefts must be interpreted as a set of 'paired contrastive foci' ("Taro's liking Hanako, Hiroshi's liking Mayumi," etc.), yet an appropriate pragmatic context is not too easy to imagine for (9b). A discourse like (10) below perhaps provides such a context, and the multiple clefts involving identically case-marked animate NPs in (10B) become noticeably easier to interpret.
A: Tasikani oya-wa
saisyo-no-ko-ga itiban certainly parent-Top first.child-Nom most
kawaii-toka, sinkon-dansee-wa yomesan-ga feel.affectionate.to-and newly.wed-man-Top wife-Nom kawaikute-tamaranai-toka yuu-kedo, irresistibly.affectionate-and said-but

'It's certainly true that they say parents feel most affectionate toward their first child and newlywed men feel irresistibly affectionate toward their wives, ..."

B: [tonikaku muzyoookende saikooni at.any.rate unconditionally maximally kawaii-tteyuu-no]-wa [ziityan-baatyan-ga feel.affectionate.to-said-that.which-Top grandpa-grandma-Nom mago-ga]-desyoo.

grand.child-Nom-Cop (literally) 'At any rate, it is grandparents grandchildren who feel unconditionally and maximally affectionate toward.'

We thus are led to consider that distinctness in terms of case may not play a major role in the awkwardness detected in (9b) either.

The above observations lead us to a more general potential theoretical problem. Among the numerous examples reported to involve Distinctness violations, quite a few are only relatively less acceptable rather than completely unacceptable. Yet if Distinctness violations represent a grammatical problem caused by the crash of a derivation as prescribed by the Distinctness Condition (4), they should be much more clearly unacceptable 
due to their ungrammaticality. The multiple clefts in (9b) in Japanese, for instance, involve only some amount of awkwardness and are not judged totally unacceptable. Likewise, the Distinctness violation claimed to arise from consecutive $a$-marked DPs in Spanish seems to be merely "not perfectly well-formed" (p. 31) relative to their improvement in DPs avoiding such a violation through movement, heaviness, and a prosodic break (Richards' ??(60) versus $(61 \mathrm{a}-\mathrm{c}))$. In Kinande, the optionality and dispreference of a 'linker' for the VP-internal multiple DPs (Richards' (203) and (204)) may present another similar case. If a linker is $v_{\mathrm{C}}$ and creates a strong phrase, it should either exist or not exist- that is, the derivation should either converge or crash.

The situation is similar for multiple $w h$-fronting in Serbo-Croatian, where Distinctness is discussed in terms of case and gender. The crucial contrasts do not involve any clear ungrammaticality (e.g. Richards' ??(107a), ?(109) versus (108)). My informants also confirm that the sentence allegedly involving the failure of distinctness in terms of case and masculine as in (11a) below (Richards' (111)) improves greatly when we replace which man and which boy with which father and which son, respectively, as in (11b).

(11) a.??Kojeg je čovjeka kojeg dječaka sram? which.Gen Aux man.Gen which.Gen boy.Gen ashamed 'Which man is ashamed of which boy?'

b. Kojeg je oca kojeg sina sram? which.Gen Aux father.Gen which.Gen son.Gen ashamed 'Which father is ashamed of which son?'

We did not alter any case or gender marking between the two sentences in (11). All we did in (11b) was to provide the arguments that presumably make it easy to imagine a pragmatic context in which a pair-list interpretation of "X being ashamed of Y" makes sense.

Thus, some cases alleged to involve a Distinctness violation exhibit only a somewhat lowered acceptability, and even this lowered acceptability can often be improved with an appropriate pragmatic context. These observations suggest that the nature of these problems is extra-grammatical rather than grammatical. We thus are led to consider that at least some of the empirical phenomena dealt with in Chapter 2 reside outside the realm of the notion 'Distinctness violation' being advocated there. It perhaps is not impossible to treat such gradient judgments by appealing to an optimalitytheoretic approach, possibly limiting its range of application to the phonology-syntax interface as in Pesetsky (1998). That is not, however, what is being pursued in Richards' monograph, and such an account of the observed 
phenomena probably cannot be put forth too easily in his approach without threatening the integrity of the notion 'grammar.'

Some fundamental questions also remain unanswered. First, why must Linearization be ordered before Late Insertion (cf. (3d))? Such an assumption effectively makes phonetic content irrelevant to linearization, yet it is generally considered that the goal of linearization is to make phonetic content pronounceable and abstract features perhaps need no linearization to begin with. It therefore strikes us as quite strange that the linearization of phonetically null and hence unpronounced functional categories like $v$ 's must be constrained. Second, it is also unclear why a feature like animacy, which is semantic in nature, plays a role in the determination of Distinctness. Third, it is argued with an example like (12) below (Richards' (64)) that what matters in the determination of Distinctness is whether or not a pair of nodes in a linearization statement $\langle\alpha, \alpha\rangle$ are located within the same Spell-Out domain rather than their string adjacency. A Distinctness violation not involving string adjacency as in this case makes us wonder whether Distinctness defined in the monograph really has anything at all to do with the linearization of phonetic content.

(12) * "It's cold," [ [vc told] [vp [John] sadly [Mary]]

Fourth and finally, as discussed above with examples from Japanese, there may also exist some phenomena that have an independent source of awkwardness whose adverse effect is only enhanced by a sequence of semantically non-distinct elements. In fact, even the examples similar to (13a, b) below (Richards' $(2 \mathrm{a}, \mathrm{b})$ ), which are presented in this monograph as clearcut ungrammatical sentences, are reported not to be uniformly rejected (Lasnik (2011)):

(13) a. *I know everyone insulted someone, but I don't know [DP who] [DP whom]

b. *I know every man insulted a woman, but I don't know [DP which man] [DP which woman]

Among the sixteen informants I consulted with, only four straightforwardly rejected both of $(13 a, b)$. All other speakers found (13b) noticeably better, if a little strange, especially after it was pointed out that the intended interpretation of the multiple $w h$-phrases is a pair-list reading. Two speakers told me that both of $(13 \mathrm{a}, \mathrm{b})$ become acceptable when they assign an emphatic stress to both $w h$-phrases. As such, the situation is somewhat similar to that of the Japanese examples above. This type of variance among speakers and/or sentences appears to indicate the involvement of one or more extra-grammatical sources of awkwardness. 
It is possible that this monograph might have erroneously included several phenomena that the proposed grammatical condition on Distinctness should actually not be concerned with. If so, then by redefining its range of empirical investigation, it might be possible to make the Distinctness condition simpler and tighter (regardless of whether linearization of phonetic content turns out to be relevant). In this regard, a careful sorting of the empirical facts seems inevitable in this extremely interesting and valuable research project.

\subsection{Prosodic Boundaries and $W h$-questions}

In Chapter 3, Richards attempts to advocate a large-scale view of the universal aspects as well as the crosslinguistic variation in $w h$-questions. First, it is claimed phonology universally constrains wh-questions: in every language, wh-questions are formed in such a way as to ensure the wh-phrase and its associated complementizer (Comp) are separated by as few minor phrase (MiP) boundaries as possible. Second, it is claimed languages vary systematically due to the interaction of phonology and syntax. In particular, whether a language syntactically derives a wh-question through overt $w h$-movement or whether it does so through $w h$-in-situ can be predicted based on the following two factors:

(14) a. Whether prosodic representations in the language are constructed by mapping (i) the left boundary or (ii) the right boundary of a syntactic phrase onto the boundary of a prosodic category, in particular of MiP.

b. Whether the language is (i) Comp-initial or (ii) Comp-final.

Richards assumes that formation of a prosodic wh-domain automatically performs a restructuring of the existing MiP phrasing, "allowing Minor Phrases to be recursive, with multiple Minor Phrases being composed into a single, overarching Minor Phrase," (p. 149) which Shinya et al. (2004) call Superordinate $\mathrm{MiP}$ (SMiP). For example, the schematized prosodic representation in (15) below might come to be mapped onto that in (16) when a SMiP containing a wh-phrase and its associated Comp is successfully created, resulting in well-formed $w h$-in-situ.

(15) C [Mip] [Mip $][$ MipWh]

(16) $\left[\mathrm{C} \quad \mathbf{w h}_{\longleftarrow \mathrm{SMiP}}\right]$

On the other hand, if the SMiP created by the formation of a wh-domain fails to contain its associated Comp as in (17) below, the wh-phrase must move toward the Comp to reduce the number of intervening MiP boundaries, resulting in overt $w h$-movement. 
(17)

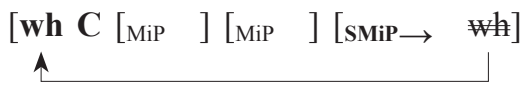

In other words, how a $w h$-question is syntactically represented in a given language depends on whether the SMiP boundary and Comp are located on one same side of the base-generated wh-phrase (resulting in overt movement), as in (17), or on the opposite sides of the wh-phrase (resulting in $w h$-in-situ), as in (16). In a nutshell, the proposed system "permits overt wh-movement just in case it improves the prosodic structure of the wh-question" (p. 155). Richards emphasizes throughout Chapter 3 (pp. 148, 155, $185,190)$ that his approach is concerned only with phonological representations and not with their phonetic implementation, hence wh-domains need not be associated with any (particular) phonetic effect. In other words, all he is concerned with is whether or not MiP boundaries intervene between a wh-phrase and its associated Comp, whatever phonetic effects this may have.

(18) and (19) below are the grammatical devices Richards adopts in this approach.

(18) Algorithm for prosodic wh-domain formation (Richards' (10))

a. For one end of the larger Minor Phrase (= SMiP $[\mathrm{YK}]$ ), use a Minor Phrase boundary that was introduced by a whphrase.

b. For the other end of the larger Minor Phrase (= SMiP [YK]), use any existing Minor Phrase boundary.

(19) Condition on prosodic wh-domains (Richards' (13))

Given a wh-phrase $\alpha$ and a complementizer $\mathrm{C}$ where $\alpha$ takes scope, $\alpha$ and $\mathrm{C}$ must be separated by as few Minor Phrase boundaries as possible, for some level of Minor Phrasing (= SMiP $[\mathrm{YK}]){ }^{1}$

This approach predicts the existence of four types of languages, as summarized in (20) below (Richards' (76) with some reorganization). Richards attempts to verify this prediction by examining each of the languages listed here (and a few others) as representative examples.

1 Note that this seems to be based on the assumption that the original MiP boundaries in (15) are eliminated in the formation of a wh-domain rather than recursively represented. 


\begin{tabular}{|l|c|c|}
\hline$(20)$ & C to right of TP & C to left of TP \\
\hline $\begin{array}{l}\text { Prosodic boundaries to } \\
\text { left of XPs }\end{array}$ & $\begin{array}{c}\text { (i) Japanese } \\
(w h \text {-in-situ) }\end{array}$ & $\begin{array}{c}\text { (iii) Tagalog } \\
(w h \text {-move, L) }\end{array}$ \\
\hline $\begin{array}{l}\text { Prosodic boundaries to } \\
\text { right of XPs }\end{array}$ & $\begin{array}{c}\text { (ii) Basque } \\
(w h \text {-move, R) }\end{array}$ & $\begin{array}{c}\text { (iv) Chicheŵa } \\
(w h \text {-in-situ) }\end{array}$ \\
\hline
\end{tabular}

(20i) $\quad<_{\text {SMiP } \rightarrow} \rightarrow$ wh $\ldots \ldots$ C $>\quad$ wh-in-situ Japanese

(20ii) $<\ldots$ wh $\leftarrow$ SMiP $>\ldots$ C $w h$-move to right ${ }^{2}$ Basque

(20iii) $\mathbf{C} \ldots<_{\mathrm{SMiP}} \rightarrow$ wh $\ldots>\quad$ wh-move to left $\quad$ Tagalog A

(20iv) $<\mathbf{C} \ldots \ldots$ wh $\leftarrow$ SMiP $>\quad w h$-in-situ Chichewa

Richards is careful to acknowledge a potential theoretical problem involved in this approach, beginning his investigation by stating, "throughout this chapter I will make very unorthodox assumptions about the interaction between the syntax and the phonology; ... the idea will be that the syntactic operation of overt $w h$-movement takes place just in case the prosody requires it. The approach therefore involves a straightforward type of lookahead." (pp. 145-146) Referring to a similar look-ahead problem involving Quantifier Raising, he also remarks, "Taken together, the look-ahead problems suggest that our understanding of the interfaces is flawed in some way." (p. 215, fn. 1)

Richards' proposal is highly valuable and meritorious in several respects. To begin with, it seriously examines the interaction of prosody and syntax, a topic which has long been regarded as important but has not been too actively investigated in the study of generative syntax. Even more admirable is that this topic is being pursued in a typological framework, a highly ambitious project to say the least.

The proposal is also valuable in more concrete terms because of the relatively high degree of falsifiability it offers. The typological predictions made in the proposed approach are directly testable since all languages are expected to involve a clear and simple correlation between the directionality of the Comp head and the placement of MiP boundaries on the one hand, and the way wh-questions are realized in syntax on the other.

Another respect in which I find the proposed approach praiseworthy is

2 Basque, in fact, does not behave this way, and Richards adopts the scrambling of a non-wh-phrase to achieve a similar effect. (p. 164) 
that it clearly acknowledges the limitation of the existing syntactic mechanisms that force overt movement by appealing to 'strong features' (or 'EPP features'), characterizing them as mere stipulations (p. 143). In fact, Richards directly rejects the use of such mechanisms as a potential solution to the look-ahead problem, pointing out that this would offer "no way of explaining the absence of complementizer-final languages with obligatory overt wh-movement to the left periphery of the clause" (p. 155).

For the proposed approach to gain firm support within the minimalist program, two essential tasks must be fulfilled. First, the approach must be demonstrated to be empirically plausible by evaluating its predictions with data from as many languages as possible. Second, the look-ahead problem must be solved somehow, presumably either by revising the model of the language faculty itself or by devising a way to solve the problem within the current model. This certainly is too serious and fundamental a problem to be left unsolved.

Richards' empirical investigation to confirm the typological predictions made by the proposed approach begins with the examination of Japanese, a relatively well-studied language with $w h$-in-situ and clause-final Comp, cf. (20i). For Japanese, he points out the following: (i) many authors have posited left boundary placement in the prosodic phonology (e.g. Selkirk and Tateishi $(1988,1991)$ ), (ii) it has long been pointed out that prosodic wh-domains are phonetically distinctive (e.g. Pierrehumbert and Beckman (1988) and Maekawa (1991)), and (iii) several authors have argued for a grammatical encoding of the correlation between the prosodic wh-domain and the scope domain of $w h$-focus (e.g. Deguchi and Kitagawa (2002), Ishihara (2003)). In (21) below, the prosodic wh-domain typically realized in Tokyo Japanese is indicated on the example sentence as follows: the whfocus is enclosed by a box and its pitch prominence is indicated by boldface, the pitch-range compression by "post-focal reduction" is indicated by the underlined reduced fonts (up to the associated Comp), and the utterancefinal interrogative rise is indicated by a question mark. The moras that are associated with high tones are indicated by upper case letters, whether their pitch ranges are reduced or not. This coding scheme will be used throughout Section 3 later on. The example sentence and its pitch track in (21) are from Ishihara (2003: 53) (Richards' (2b)).
NAoya-ga
NAni-o noMIya-de NOnda-no? Naoya-Nom what-Acc bar-at drank-Compwh 'What did Naoya drink at the bar?' 


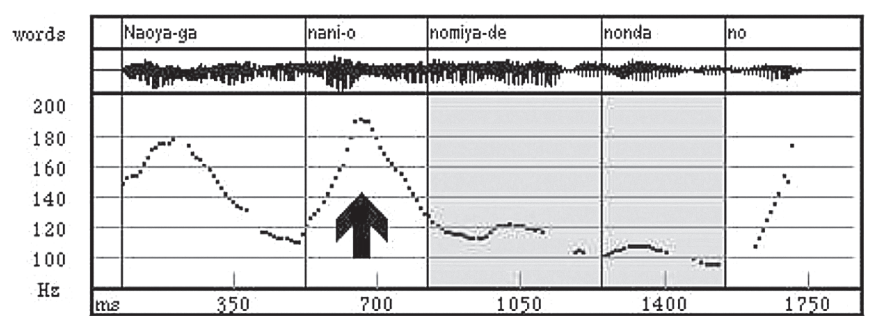

Richards claims that Japanese verifies the existence of a language of the type in (20i), exemplifying a wh-in-situ language involving left boundary placement $((i)$ above) and Comp-finality.

$$
\text { (20i) } \quad<_{\text {SMiP } \rightarrow} \text { wh } \ldots . . . \text { C }>\text { wh-in-situ Japanese }
$$

Japanese indeed presents a very clear case demonstrating the correlation between $w h$-in-situ and prosody with its distinctive prosodic wh-domain ranging from the wh-word to the Comp, which also correlates with the scope domain of wh-focus ((ii) and (iii) above). Thus, the evaluation of the typological predictions in (20) appears to be off to a good start.

The prosodic structure postulated for (20i) in Japanese, however, is not without problems. It has been repeatedly noted in the literature that the LHL contour involved in the reduced items in (21) (noMlya-de 'bar-at' and NOnda 'drank') is compressed but has not entirely disappeared, as can be observed in the pitch-track diagram in (21) (Maekawa (1994), Kitagawa (2005), Ishihara (2011)). Since the initial rise (LH) is observed in these prosodic words, their MiP boundaries must have been retained, contrary to the prosodic structure assumed for (20i).

The other three typological varieties in (20ii-iv), in fact, are not as cleanly attested. First, (Ondarroa) Basque is proposed as a language of the type in (20ii).

$$
\text { (20ii) }<\ldots \text { wh } \leftarrow \text { SMiP }>\ldots \mathbf{C} \text { wh-move to right Basque }
$$

Based upon previous research, it is concluded that a MiP boundary in this language is placed at the right edge of a phrase (though only under specific circumstances). Being a head-final language, it is also assumed that Comp is located to the right of the clause in Basque (though is phonetically 'invisible'). It is therefore predicted that Basque should permit rightward whmovement to Comp, as in (20ii). In reality, however, a wh-phrase in this language appears immediately before a verb as in (22) below, rather than in its base-generated position as in (23a) or in the landing site of rightward wh-movement to Comp as in (23b). 
(22)

Jon señek sMip $>$
Jon-abs who-erg
'Who saw Jon?'

ikusi rau-C? see-prf aux.pr

(Richards' (29a))

Richards follows Arregi (2002) in assuming that (22) is derived by "altruistic" scrambling of the non-wh-phrase as in (24).

$\begin{array}{lllll}\text { (24) Jon } & \text { señek } & \text { Jen } & \text { ikusi } & \text { rau? } \\ \text { Jon-abs } & \text { who-erg } & \text { see-prf } & \text { aux.pr }\end{array}$

Note that only one MiP boundary intervenes between the wh and Comp in (22) as opposed to two in (23a), achieving improvement in prosodic structure, although both sentences involve $w h$-in-situ rather than whmovement. With this analysis, Richards concludes that "the condition on prosody will thus have to be stated as an economy condition, requiring the grammar to 'do its best' to minimize the number of Minor Phrase boundaries between the $w h$-phrase and the complementizer; ..." (p. 164).

To cope with the problem of there being no rightward wh-movement to Comp as in (23b), Richards cites Elordieta's (1997) observation that the pitch of the postverbal material in Basque is always radically compressed. He ultimately settles on the view that "postverbal material in Basque is already subject to conditions on prosody which might be incompatible with the conditions on wh-prosody being explored here" (p. 163). This may indeed turn out to be the reason why rightward whmovement to Comp is not observed in Basque. However, in order for this account to be valid, the incompatibility assumed here must be shown to involve prosodic phrasing. (Recall that the proposed approach concerns only prosodic phrasing and not its phonetic implementation.) Presumably, whatever causes prosodic reduction of the postverbal materials must require the existence of more than one intervening MiP boundary between the moved wh and Comp in (23b). What is even more pressingly required of the proposed approach, though, is an account of why rightward overt wh-movement is virtually unattested in spoken languages. ${ }^{3}$ If prosodic boundary place-

3 See Cecchetto et al. (2009) for the claim that wh-phrases undergo rightward movement in various sign languages. 
ment on the left and Comp-finality are both attested as widely available options, then such a gap in the typology poses a serious problem to the proposed approach. It appears that much work is yet to be done in this area.

Tagalog is proposed as a language of the type in (20iii).

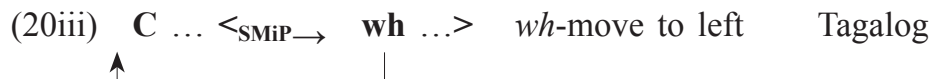

Based upon his own pilot study, Richards concludes that MiP boundaries in this language are generally placed at the left edges of KPs (which is claimed to be a phase). Since Tagalog is a Comp-initial language (though Comp is phonetically invisible in matrix clauses), it is predicted to involve obligatory leftward $w h$-movement. This prediction is upheld:
a. Kailan C umuwi si Juan < SMip kailan? when Nom-went.home Ang Juan when
'When did Juan go home?'
(Richards' (59))

A different prediction made under this approach is not borne out, however. Richards notes that the MiP boundary immediately following the verb is deleted due to "an overriding requirement that the verb not be in a phrase by itself" (p. 171), hence the lack of a MiP boundary after umuwi in (25) above. As such, wh-in-situ should be possible in immediately post-verbal position, as in (26).

(26) $\mathbf{C} \quad \mathbf{V}<{ }_{\text {Mip }}$ wh ...

Such a construction, however, is not generally possible. The only exception is when one particular wh word nino 'who' is used, and even this is only marginally permitted (especially when other items follow it). Thus, while Tagalog generally is of type (20iii), the difficulty of $w h$-in-situ in (26) casts a shadow over the integrity of the overall typological predictions.

Chichewa is proposed as a language of the type in (20iv).

$$
\text { (20iv) }<\mathbf{C} \ldots \ldots \text { wh } \leftarrow \text { SMiP }>\quad w h \text {-in-situ Chicheŵa }
$$

In this language, the vowel in the penultimate syllable of a phonological phrase is lengthened, and an underlying $\mathrm{H}$ tone is retracted from the final mora onto this lengthened penultimate mora (e.g. mlendó 'visitor' $\rightarrow$ mleéndo: Kanerva (1989), Truckenbrodt (1999)), suggesting MiP boundaries in this language are placed at the right edge of phrases. In addition, since Chichewa is a head-initial language, Comp falls to the left of the associated clause (though it is phonetically invisible in matrix clauses). Based on these two observations, Chichewa is predicted to permit wh-in-situ, and indeed, the position of the wh-word in (27) below confirms this predic- 
tion. (Examples (27) and (28) are Richards' (69) and (70), which are both cited from Downing (2005).)

(27) <C anaményá chiyáani sMip $>$ ndi mwáálá MiP> he.hit what with rock

'What did he hit with the rock?'

Upon closer examination, however, a phenomenon is observed here that is unexpected under the proposed approach. Typically, a VP in Chicheŵa is mapped onto a single MiP without any internal prosodic boundaries, as is confirmed by a comparison of the underlined vowels in the following example:

$\begin{array}{clll}\text { <anaményá nyumbá ndí mwáálá } & \text { MiP> } \\ \text { he.hit } & \text { house with rock } & \end{array}$

'He hit the house with the rock'

However, a SMiP boundary does appear within the VP in (27) (as indicated by the lengthening and $\mathrm{H}$ tone on the penultimate syllable of the $w h$-word). This suggests that, contrary to the claim being made, it may in fact not be advisable to attempt to characterize prosodic wh-domains in Chichewa by appealing to the general prosodic phrasing in the language.

Richards also analyzes French as exemplifying the type in (20iv).
(20iv)
$<\mathrm{C} \ldots \ldots$ wh $\leftarrow$ SMiP $>$
wh-in-situ
Chichewa

French has head-initial Comp and is claimed to impose metrical boundaries at the right edge of maximal projections. As predicted in the proposed approach, French exhibits $w h$-in-situ just as in Chichewaa. One complication, however, is that $w h$-questions via movement can also be formed, as illustrated in (29b).

(29) French (Richards' (95))
a. $\quad<\mathrm{C}$ Tu as vu qui smip $>$ ?
you have seen who
'Who did you see?'
b. <Qui C tu as vu qui sMip>?

Richards does in fact note that leftward wh-movement ought to also be an option for the languages of the type in (20iv) under the proposed approach "as long as the movement improves the prosodic structure of the question" (p. 155). If so, then it must be the case that the MiP boundaries within the SMiP created by the $w h$-phrase in (20iv) are erased in cases of $w h$-in-situ but somehow maintained in cases of wh-movement. It is not clear how this state of affairs can be obtained, but this is precisely what must be confirmed in order to provide evidence for the proposed approach. 
2.3. Phase for 'Look-ahead'

Finally, in the concluding section of Chapter 3, a new potential solution for the look-ahead problem (mentioned in the paragraph below the table (20) in Section 2.2 above) is offered. It starts with the claim that the only syntactic maximal projections relevant to prosodic boundary marking are 'phases' (Chomsky (2001)). It is assumed that all material in the sister domain of the phase head are sent to PF by Spell-Out, while the material at the edge remains part of the syntactic computation. At PF, prosodic boundaries are inserted "on the right or left edge of the phase," (p. 201) and "the PF component returns to the syntax an object that has been partly annotated for prosody." (p. 202) In this way, the type of phonological information relevant to syntax is determined via Spell-Out before the syntactic derivation is complete, and the application of $w h$-movement in syntax does not have to 'look-ahead' for the satisfaction of the phonological condition.

An appeal to the notion of a phase offers a new kind of 'window' through which we can view the prosody-syntax interaction in new ways, which may provide solutions to some of the potential problems of the originally proposed approach pointed out in Section 2.2 above. However, since the details of this approach are not spelled out and virtually no independent supporting arguments are provided, it is difficult to see how this approach can actually do everything it is claimed to do. For instance, a question that immediately arises is how Spell-Out can establish the prosodic boundaries of the phase at PF while its edge (and hence the higher of its syntactic boundaries) has yet to be sent there. (Recall that what is sent to PF by Spell-Out is the material in the sister domain of the phase head, not the material of the entire phase.) It is difficult to imagine how Spell-Out makes it possible for a prosodic boundary of the phase to be inserted in the phonology without the presence of its corresponding syntactic boundary. The assumption that PF can selectively return certain types of prosodic information to syntax is also an entirely new claim that calls for full-scale justification. In fact, it is not even clear if there is any substantial difference between claiming that "phonology returns to the syntax some aspects of phonology" and claiming that "syntax can look-ahead and access aspects of phonology." Thus, even if we take into consideration that the proposed phase approach was offered only as a premature potential solution, it does not solve the look-ahead problem in question in any straightforward way. 


\section{Synchronization of Sounds and Meanings}

Richards' investigation of the prosody-syntax interaction makes clear, simple, and valuable typological predictions. The above cross-linguistic examination demonstrates that the predicted language types in (20i-iv) are indeed existent, except for that in (20ii). At the same time, however, serious unsolved problems and/or unanswered questions have been posed for each of the four cases (including type (20i) as exemplified by Japanese). The fact that all of these problems/questions concern the phonological representation of prosodic phrasing casts a shadow over the integrity of the typological predictions based upon prosodic phrasing. Moreover, as argued above, we must also conclude that the look-ahead problem still persists in the proposed approach. Given this state of affairs, I feel compelled to shy away from the present attempt to explain the typological variation of wh-questions by appealing to prosodic phrasing.

In closing his monograph, Richards states:

"The theories presented here raise many questions for possible further study. Like any explanations, my explanations have to stop somewhere, and we should ask whether still deeper levels of explanation are possible. Why should a wh-phrase and its scope position have to share a prosodic domain? [emphasis by YK]" (p. 206)

In this section, we will attempt to provide an answer to the question asked at the end of this quote. We believe that a proper answer to this question will approach the syntactic typology of $w h$-questions without recourse to prosodic phrasing and in a way that avoids the look-ahead problem.

\subsection{Physical Marking for Logical Interpretations}

While we are no longer able to maintain that general prosodic phrasing plays a key role in the typology of wh-questions, we still have reason to believe that Richards is heading toward the right direction in his investigation of this topic. In particular, it strikes us as a correct generalization to claim that overt wh-movement applies when a language fails to supply an appropriate prosodic wh-domain, and to claim that that the position of Comp plays an important role in this syntactic choice. At the core of this generalization is Wachowicz's (1978) idea that all languages must provide some form of surface physical cues for marking wh-questions and Cheng and Rooryk's (2000) claim that prosody can function as one of such cues. Elaborating further on this view, we hypothesize that assigning a distinctive $w h$-prosodic pattern and moving a $w h$-phrase to the periphery of $\mathrm{CP}$ 
share the same PF-function of physically indicating wh-questions.

Along these lines, Deguchi and Kitagawa (2002) and Kitagawa (2005) argue that $w h$-prosody physically marks the interpretive scope domain of $w h$ questions in Tokyo Japanese. For example, a potentially ambiguous question can be disambiguated with prosody, as illustrated in (30) and (31). ${ }^{4}$

$$
\begin{array}{llll}
\text { (30) [CP1 JYOn-wa [CP2 MEarii-ga NAni-o katTA-ka] } & \text { Imademo } \\
\text { John-Top Mary-Nom what-Acc bought-Comp } & \text { wthr } & \text { even.now } \\
\text { siRITAGAtteiru-no? } & & & \\
\text { want.to.know-Comp } & & & \\
\text { (literally) 'What does John still want to learn whether Mary } \\
\text { bought?' }
\end{array}
$$

In (30), the prosodic domain extends to the matrix Comp -no (as evidenced by the post-focal reduction being prolonged to the end of the utterance), and the subordinate $w h$-phrase takes matrix scope. In (31), on the other hand, the prosodic domain is terminated at the subordinate Comp, and the whphrase takes subordinate scope.

The contrast just discussed indicates that prosody plays an important role to physically mark the interpretive domain of $w h$-focus, reinforcing the overt question marker (e.g. -ka/-no in Japanese). Quite interestingly, it has also been reported that prosodic wh-domains in Fukuoka Japanese show similar patterns but are realized in a phonetically different way (Kubo (1989) and Smith (2005)). The contour for Fukuoka Japanese, illustrated in (32) below (from Smith (2013: 120)), starts with a rise on the wh-word, after which high pitch (indicated by underlined capital letters) is maintained until the end of the wh-scope domain, and then ends with an utterance-final interrogative rising contour as in (32). (We will examine a potentially ambiguous case in Fukuoka Japanese similar to (30) and (31) in Section 3.2.4.1 below.)

\footnotetext{
${ }^{4}$ In glosses of these and other examples, each distinct function of complementizers in Japanese is indicated as Comp $\mathrm{Wh}_{\mathrm{Wh}}\left(w h\right.$-scope maker), Comp $\mathrm{W}_{\mathrm{W} \text { thr }}$ (a polar-question complementizer), Comp $\mathrm{Y}_{\mathrm{N}}$ (yes/no question marker) and Comp $\mathrm{P}_{\text {That }}$ (declarative complementizer). Recall also the notation for indicating prosody on linguistic examples described in the paragraph above (21).
} 
(32)

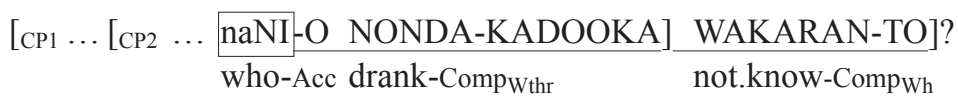

(literally) 'What doesn't X know whether Y drank?'

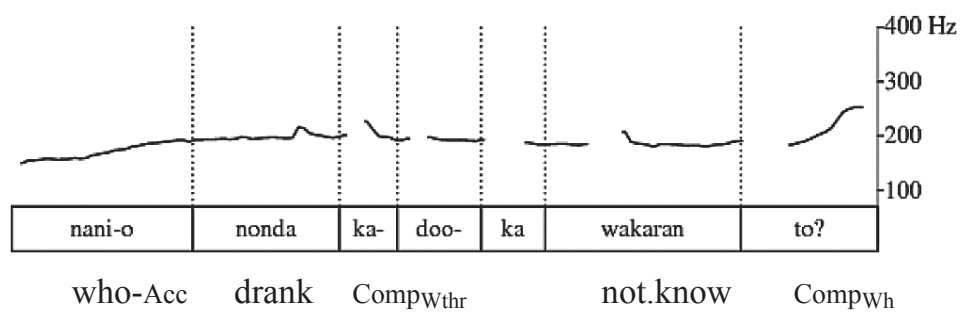

Let us now hypothesize that whatever method of physical marking may be adopted for wh-questions (assigning a distinctive wh-prosodic pattern or moving a wh-phrase to the periphery of $\mathrm{CP}$, etc.), its primary purpose is to indicate both of the following: ${ }^{5}$

(33) a. The item to be interpreted as focus

b. The constituent which constitutes its scope domain

To fulfill (33a), the $w h$-focus itself is generally expressed with a morpheme or word belonging to a special class, i.e. wh-words. In addition, languages also involve the additional physical marking of the $w h$-focus word itself. To fulfill (33b), the beginning or the end of the wh-focus domain is also physically signaled. In performing the two tasks in (33), the following three elements naturally play a significant role: the position of the wh-phrase, the position of its associated Comp, and the prosody across the region of the sentence between the two. When we reanalyze the language types in (20i-iv) paying attention only to the positions of the wh-phrase and Comp (rather than to prosodic phrasing), we obtain $(34 \mathrm{i}-\mathrm{iv}){ }^{6}$

5 At this point, we settle for this informal statement of the generalization, postponing its formalization to Section 3.2.

${ }^{6}$ Note that we have not added anything new or extra to Richards' approach by revising (20i-iv) into (34i-iv). All we have done is to avoid any appeal to prosodic phrasing. Note also that Richards' condition on wh-prosody in (19) also appeals to the notions of wh-phrase and Comp in defining a wh-domain. In the end, we will reach an analysis in which the linear position of Comp plays a less crucial role. 


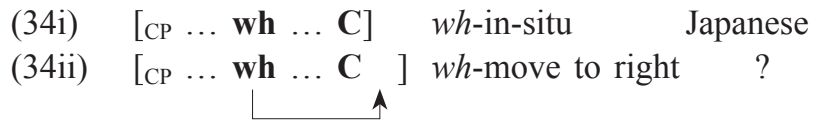

(34iii) $\left[\begin{array}{lllll}\mathrm{CP} & \mathbf{C} & \ldots & \mathbf{w h} & \ldots . .\end{array}\right]$ wh-move to left English/Tagalog

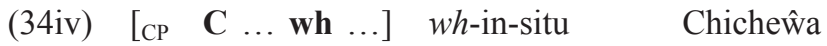

This generates several typological predictions, which we will now evaluate in turn. First, it appears that the physical marking of a wh-question in languages of type (34i) is typically carried out via prosody. In Tokyo Japanese, for instance, focus prominence is placed on the wh-item in the form of elevated high pitch accent, thus physically marking its focus status and fulfilling (33a). Moreover, the terminating point of the post-focal reduction indicates that the end of the CP is the scope domain for wh-focus, thus fulfilling (33b). (Refer back to (30) and (31) above as well as the pitch-track diagram in (21).) Since this analysis does not make reference to prosodic phrasing, the presence of MiP boundaries within the post-focal domain (as discussed in Section 2.2 above) does not pose any problem, unlike in the prosodic boundary approach.

In Comp-initial languages like English and Tagalog, for which no such prosodic marking is available, the physical marking of a wh-question is achieved by overt wh-movement, thus representing the language type in (34iii). Having been displaced from its base-generated position and placed at the left periphery of the clause, the overtly-moved wh-phrase comes to be identified as the item to be interpreted as focus. Since the moved whphrase must land in the vicinity of the invisible Comp at the beginning of the clause, the scope domain of $w h$-focus can be automatically identified as the maximal projection of this Comp (CP). ${ }^{7}$ In a sense, leftward overt wh-movement in Comp-initial languages can be characterized as an efficient way to physically mark all the pieces of information necessary for the interpretation of $w h$-questions. First, the item to be interpreted as focus is clearly indicated since it has been dislocated. Moreover, the whfocus interpretive domain is also clearly indicated since it corresponds to the maximal projection of the Comp having the specifier position to which the wh-phrase has been dislocated. The movement strategy is adopted also in Tagalog, as observed in (25a) above. Recall that the absence of wh-

${ }^{7}$ For the sake of simplification, we will not take into consideration the 'split CP' analysis as in Rizzi (1997). 
in-situ in the immediately post-verbal position in this language, as in (26), remained unaccounted for in the prosodic boundary approach. In contrast, this does not pose any problem for the proposed 'physical marking' analysis since it does not appeal to prosodic phrasing.

The language type in (34iv) also corresponds to Comp-initial languages, but this time to ones for which the physical marking of a wh-question can be carried out by prosody. Although Chichewa presumably is a language of this type, the literature often reports difficulty recognizing any particular prosodic properties distinctively associated with wh-questions in this language. Myers (1996: footnote 1, p. 29), for instance, is forced to pigeonhole their description because of "a great deal of variation both within and between speakers." Downing (2011: 32) reports that she finds no distinctive prosodic properties for $w h$-question other than a raised overall pitch. Downing and Pompino-Marschall (2013: 9-10, 16), however, present a quite interesting discussion which has a potential to explain how such difficulty arises. They first report their experimental results on the prosody involved in the answers to $w h$-questions in Ntcheu Chichewa as in $(35 \mathrm{a}, \mathrm{b})$.

(35) a. Broad focus: (pp. 9, 16)

Q: Chí-na-chitíka ndi chi-yáni?

7SBJ-TAM-happen COP 7-what

'WHAT HAPPENED?'

A: Mwaná a-ná-menya nyumbá ndí mwalá. 1-child 1SBJ-TAM-hit 9.house with 3.rock

'THE CHILD HIT THE HOUSE WITH A ROCK.'

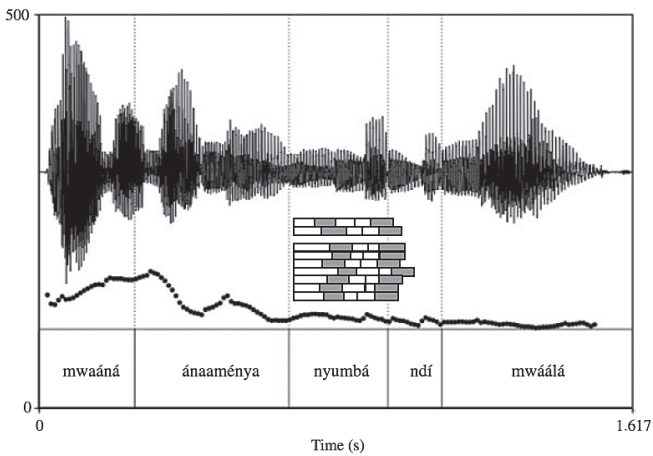

b. Narrow focus: (pp. 10, 16)

Q: Mwaná a-ná-menya chi-yáni ndí mwalá?

1-child 1SBJ-TAM-hit 7.what with 3.rock

'WHAT did the child hit with the rock?' 
A: Mwaná a-ná-menya nyumbá ndí mwalá. 1-child 1SBJ-TAM-hit 9.house with 3.rock 'The child hit THE HOUSE with a rock.'

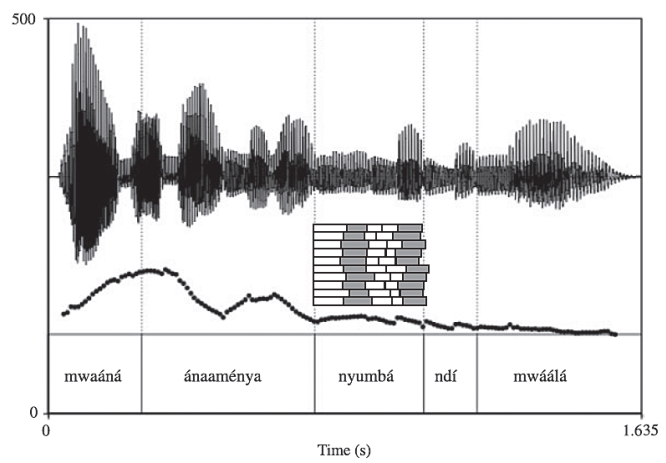

They observe first that focus is prosodically indicated only by the lengthening of the final foot of the focus domain rather than by any specific prosodic property of the focus expression itself, whether the answer to a wh-question involves broad focus as in (35a-A) or narrow focus as in (35bA). As a result, narrow and broad foci in Ntcheu Chichewa are prosodically indistinguishable in most cases, as illustrated by the two pitch-track diagrams in (35). Downing and Pompino-Marschall also report, however, that some speakers assign a distinct prosodic pattern as in (36) below when they provide an answer to a wh-question involving narrow focus as in (35bQ). (II indicates a pause.)

(36) Narrow focus: (pp. 5, 23)
A: A-na-mény-á
NYUMBÁ || ndí mwáálá.
1-SBJ-RECENT.PAST-hit 9.house
with 3.rock
'S/he hit the HOUSE with a rock.'

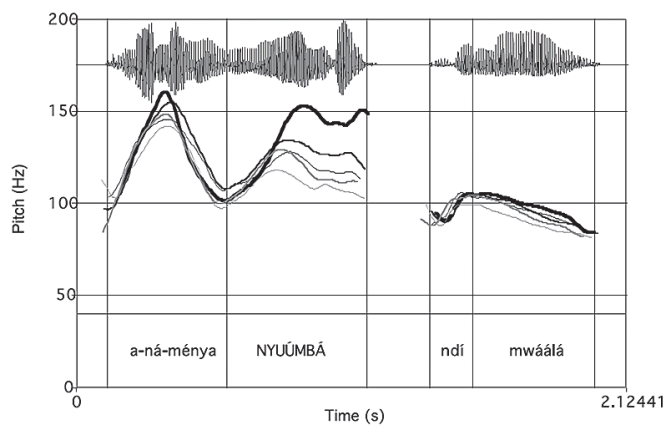

As indicated by the pitch-track diagram in (36), the pitch of the focused 
word is raised, thus disturbing the expected downstep. The raised pitch is then followed by a steep fall into the pause. As a result, the High tone associated with the post-focal word is realized noticeably lower and makes the focused element prominent. Downing et al. (2004: 177) called this an 'anti-accent' effect and regarded it as a distinctive focus prosodic pattern in Chichewa. In order to reconcile these seemingly contradictory experimental results, Downing and Pompino-Marschall proposed to regard the prosodic pattern in (36) as what they call emphatic prosody, which is optionally assigned when speakers would like to indicate narrow focus disambiguously. Suppose now that, as Downing and Pompino-Marschall claim, narrow and broad foci in Chichewa are prosodically indistinguishable unless speakers adopt an option of assigning a prosodic pattern as in (36). Suppose further that permitting broader focus without making any extra prosodic effort is a default strategy Chichewa speakers generally adopt. It then is naturally expected that focus prosody is rarely and variably assigned to whquestions in this language, as has been reported in the literature. Note now that the prosodic pattern used to unambiguously indicate narrow focus in Chichewa as in (36) resembles the focus prosody observed in Tokyo Japanese in (21), where the prosodic wh-domain starts with raised pitch on the wh-focus word and ends where the post-focal reduction stops.

The above investigation of (34i), (34iii) and (34iv) suggests that a general division of labor exists between prosody and displacement to the periphery in achieving a physical marking that is associated with the interpretive implementation of $w h$-questions. ${ }^{8}$ This general picture is supported by the well-known observation that displaced $w h$-items themselves generally do not carry focus prominence in wh-movement languages (Ladd (1996: 170172)). Accordingly, we predict that wh-in-situ is accompanied by some kind of distinctive prosody while overt wh-movement is not, even in the languages that permit both options like French. These predictions appear to be upheld. Cheng and Rooryk (2000) argued that wh-in-situ in French obligatorily involves sentence-final rising intonation, which wh-movement does not. Déprez et al. (2013) empirically verify this claim in their production experiment on prosodic patterns of wh-questions like (37)-(39) below.

8 Tentatively, I assume that $w h$-movement is a more marked strategy of physical marking than wh-prosody since it involves an extra process of relocating phonetic content to the periphery of a clause, while prosody is assigned to a sentence no matter what. 
(37) Wh-movement with the question marker est-ce que:

Quel élément est-ce qu' elle a mis au milieu? which shape QUES.PRT she has placed in.the middle 'Which shape did she place in the middle?'

(38) Wh-movement with subject-auxiliary inversion:

Quel élément a-t-elle mis au milieu? which shape has.she placed in.the middle

(39) Wh-in-situ:

Ellea mis quel élément au milieu? she has placed which shape in.the middle (literally) 'She placed which shape in the middle?'

Interestingly, the final rise was assigned in the wh-in-situ construction by most, but not all, the speakers who participated in their experiment. Those who did not assign a final rise instead placed an elevated pitch on the whword itself. Déprez et al. (2013: 14) illustrate the results of their experiment with the diagrams in (40), with the left and right panels representing the pitch contours for these two different sub-groups of participants. The three contours inside each plot correspond to the three sentence types in (37)-(39).

a. High pitch accent on

b. Clause-final rising contour: the wh-word:

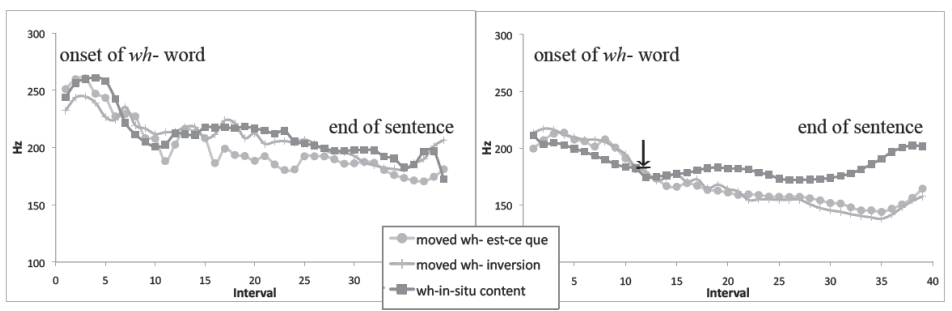

Not only did Déprez et al. (2013) find that different speakers choose between these two different strategies, but they also demonstrated that the extent of the final rise and the height of the pitch on the $w h$-word negatively correlate with each other. These two results suggest that the two patterns are likely to be variables of the prosody for $w h$-in-situ in French. Furthermore, Bayssade et al. (2007: 167-168) observe that, in the wh-question accompanied by a falling contour, the elevated high pitch accent of the wh-word is followed by a low pitch accent (and one or more low boundary tones, according to their phonological analysis). This post-focal pitch lowering is illustrated by the pitch-track diagrams $(41 \mathrm{a}, \mathrm{b})$ they provide 
and also by the diagram in (40a). (The wh-word in (41a, b) is assigned a phrasal H- in Bayssade et al.'s (2007) analysis.)

(41) a.

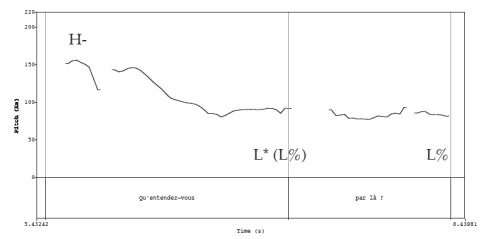

b.

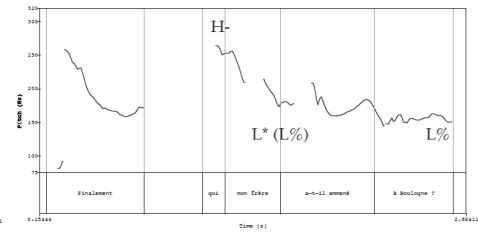

Finally, when the sentence is assigned a clause-final rising contour as in (40b), the onset of the wh-word starts with low pitch, which Déprez et al. (2013: footnote 9, p. 14) describe as "flat intonation or a compressed pitch accent" and Bayssade et al. (2007: 168) analyze as involving a phrasal L-, as in (42).

(42)

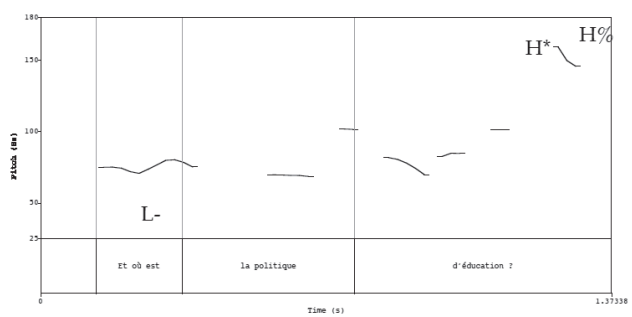

To sum up, a wh-question is realized as $w h$-in-situ in French only when a distinctive prosodic pattern for a wh-question is assigned to it (either a raised pitch on the wh-word or a final rise, depending on the speaker). Otherwise, the wh-question is realized with the application of overt wh-movement. Once again, since prosodic phrasing does not need to play any direct role in these analyses, we are not forced to assume that the two options of $w h$-questions in these languages are reduced to the presence versus absence of MiP boundaries.

When the prosodic analyses of $w h$-in-situ languages reported above are compared, a general picture emerges. In each case, a prosodic wh-domain is initiated with a $w h$-focus word and terminated at the end of the clause in which this $w h$-focus takes scope. In particular, a $w h$-focus word is marked by some local tonal event, and the end of the clause is marked by either a distinctive contour (e.g. a rise) or the termination of a stretch of low/high pitch. These findings are as summarized in (43). 
(43) Prosodic patterns in $w h$-in-situ languages:

\begin{tabular}{|l|l|l|l|}
\hline Language & Example & wh-word & End of CP \\
\hline Tokyo Japanese & $(30)$ and $(31)$ & clear pitch prominence & $\begin{array}{l}\text { end of low pitch } \\
\text { sequence }\end{array}$ \\
\hline $\begin{array}{l}\text { Fukuoka Japa- } \\
\text { nese }\end{array}$ & $(32)$ & rising contour & $\begin{array}{l}\text { end of high pitch } \\
\text { sequence }\end{array}$ \\
\hline Chichewa & $(36)$ & $\begin{array}{l}\text { some pitch prominence } \\
\text { followed by a pause }\end{array}$ & $\begin{array}{l}\text { end of low pitch } \\
\text { sequence }\end{array}$ \\
\hline French (rising) & $(54 a)(=(39))$ & compressed pitch & rising contour \\
\hline French (falling) & $(54 b)(=(39))$ & clear pitch prominence & $\begin{array}{l}\text { end of low pitch } \\
\text { sequence }\end{array}$ \\
\hline
\end{tabular}

Exploring these patterns is a first step in responding to the need for examining much fuller data like (30) and (31) in languages other than Tokyo Japanese. These generalizations in (43) will be appealed to when we attempt to grammaticalize the sound-meaning synchronization in wh-questions in Section 3.2.4.1.

What remains to be accounted for is why rightward wh-movement as in (34ii) is not observed, at least in spoken languages.

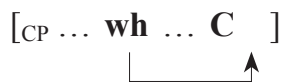
wh-move to right
?

We can surmise the reason why this option is generally avoided as follows. Recall that it is being claimed here that overt wh-movement applies in quest of some form of physical marking associable with the interpretive aspects of $w h$-questions. While leftward overt $w h$-movement can successfully signal the involvement of a $w h$-focus (and its interpretive domain) at the beginning of a clause, rightward movement cannot encode such pieces of information until the very end of the clause. Such a delay of information imaginably creates a critical handicap when this kind of question sentence is processed. It therefore seems natural that languages should shy away from adopting the grammaticalization of such an inefficient way of physically marking wh-questions.

\subsection{Grammaticalizing Sound-Meaning Correlations}

In discussing typological variation in wh-questions in general, and discussing the prosodic disambiguation of potential wh-scope ambiguity in Japanese as in (30) and (31) in particular, we paid attention only to the surface correlations between $w h$-prosody and $w h$-scope. We also offered some informal generalizations and analyses to capture this observable surface correlation as if we were assuming that prosody directly derives semantic 
effect (or vice versa). We now begin a more serious investigation of how the grammar can achieve these surface correlations. If this investigation is pursued within the minimalist program, its goal can be restated as finding a way to guarantee synchronization of a specific PF and a specific LF for a $w h$-question without giving rise to any theory/model-internal contradiction like that posed by the look-ahead problem.

\subsubsection{Overt Movement as 'Look-ahead'}

Before beginning this discussion, we first review some of the restrictions imposed on grammar by the core working hypotheses of the minimalist program. First, the input to the grammar should be nothing but the information encoded in lexical items ("Inclusiveness"). Second, the information in lexical items should be completely split so that each of the interface representations (PF and LF) consists solely of the information legible to the performance systems of sounds and meanings, respectively ("Legibility"). Third, syntactic derivation should be induced only by an interface need to derive legible PF and legible LF without involving any form of 'look-ahead' (“(Local) Economy”). These constraints imposed on grammar must always be observed in order for the minimalist program to be maintained properly. ${ }^{9}$

These fundamental requirements, however, have not always been met in the development of the theory of minimalist syntax. Overt movement, for example, has been characterized as a rule that applies before Spell-Out so that it can affect both PF and LF rather than LF alone. Note that this is a straightforward case of a look-ahead. In order to conceal this state of affairs, Chomsky $(2000,2001)$ postulates an EPP-feature, characterized as a 'virus that requires a spec' which must be eliminated before any larger constituent is created by Merge. In other words, movement is made overt at the expense of postulating an otherwise unmotivated imperfect entity that needs to be eliminated even before it reaches the interface. This approach directly disregards the local economy requirement mentioned above. Note also that, because of this tailor-made imperfection that has to be eliminated

9 In this article, the 'minimalist program' refers to a general program seeking "to discover to what extent minimal conditions of adequacy suffice to determine the nature of the right theory" (Chomsky (2000: 92)), pursued with the working hypotheses mentioned above. Crucially, the use of the term in this article does not refer to any particular mechanics or technical details Chomsky has adopted in pursuing this program, for example, postulation of specific functional categories like AGR or $v$, an appeal to a 'probe-goal relation' (or its predecessor 'feature checking') or overt Agree. 
before Spell-Out, overt movement induces displacement effects at both PF and LF accidentally. In short, the whole approach here is simply a restatement of the problem rather than a solution.

By definition, since overt movement displaces phonetic content, it affects not only the semantics of a sentence but also its pronunciation. The source of the look-ahead problem just observed is the attempt to achieve this effect by forcing its application before Spell-Out, i.e., before the derivation reaches the interface components. Yet at this point in the derivation, there is no genuine grammatical motivation for such an operation. What the grammar needs to achieve, then, is to let overt movement affect sounds and meanings separately (in accordance with an interface need to derive a well-formed PF and a well-formed LF, respectively) yet somehow guarantee their synchronized effects.

\subsubsection{Prosody-Semantics Correlations as 'Look-across'}

Recall now the correlations between wh-prosody and $w h$-scope observed for Japanese in (30) and (31). If these remain mere observations, then it remains to be explicated how exactly the grammar makes possible such correlations. A common claim found in the literature is simply that a certain prosodic pattern is responsible for producing a specific semantic effect (or vice versa), but this claim provokes a problem of local economy in the grammar comparable to the 'look-ahead' required by overt movement. The only difference is that, in this case, since an LF is derived directly from a PF (or vice versa) skipping syntax, the prosody-semantics correlation involves 'look across' rather than 'look ahead.' The task that must be undertaken by the grammar in both cases is the same-it must somehow find a way to guarantee the synchronization of a specific PF effect and a specific LF effect while finding an independent interface motivation to establish each of them.

We would like to argue in the remainder of this article that these seemingly independent issues (the 'look-ahead' problem of overt movement and the 'look-across' problem of $w h$-in-situ) can be resolved in the same way, i.e. with an appeal to the same grammatical mechanisms. The key to the solution is to strictly observe the three minimalist constraints imposed on grammar mentioned above.

\subsubsection{Synchronizing and Splitting Sounds and Meanings}

First, we will establish the synchronization of sounds and meanings in general by adopting a feature complex of the form $\left[f_{P}, f_{L}\right]$, where $f_{P}$ is a 
feature relevant to $P F$ and $f_{\mathrm{L}}$ to LF. The paired features $\left[\mathrm{f}_{\mathrm{P}}, \mathrm{f}_{\mathrm{L}}\right]$, which we call a 'PL-complex (physical/logical feature complex),' represent two different interface aspects of a single linguistic phenomenon. PL-complexes are added to lexical items, along with formal features like Case and F-features, when a Numeration (or Lexical Subarray) is formed. For instance, when a Numeration is formed for the utterance in (44) below, various extra features (among others) are added to the lexical items, as indicated in (45).

(44) [As an answer to the question 'Who does John love?']

He loves MARY.

(45) $\mathrm{N}$ : $\{$ he $(\mathrm{NOM})$, loves (PRES, 3P/SG), Mary (ACC, [FOC $\mathbf{P}$, FOC $\left.\left.\left._{\mathbf{L}}\right]\right)\right\}$

Here, because of its focused status, the lexical head of the object $\mathrm{N}_{\max / \min }$ Mary is assigned the PL-complex $\left[\mathrm{FOC}_{\mathrm{P}}, \mathrm{FOC}_{\mathrm{L}}\right]$. This PL complex consists of two distinct types of features: a phonetically interpreted focus feature $F O C_{\mathrm{P}}$ and a semantically interpreted focus feature $F O C_{\mathrm{L}}$.

When a language user consciously or unconsciously decides what lexical items are to be used in generating an utterance, he or she also determines what informational role should be assigned to each of them in accordance with the appropriate information packaging strategy for a given context. This decision leads to the introduction of PL-complexes to particular lexical items. The PL-complex $\left[\mathrm{FOC}_{\mathrm{P}}, \mathrm{FOC}_{\mathrm{L}}\right]$ was added to Mary in (45) in this way. The matter of what particular lexical items are selected into the Numeration is not determined by purely grammatical factors alone but by various extra-grammatical factors like register and style as well-as in the selection from angry, mad and pissed off. As such, we consider Numeration to be an interface between the computational component of the minimalist grammar and other cognitive systems. Likewise, information packaging, i.e., how we convey a message, rather than what we convey, is also determined by extra-syntactic factors like discourse and pragmatics. For these reasons, we consider Numeration to be the appropriate level for the introduction of PL-complexes.

The feature $f_{\mathrm{P}}$ eventually comes to be associated with some instruction to the performance system for sounds when it appears at $\mathrm{PF}$, and the feature $f_{\mathrm{L}}$ eventually comes to be associated with some instruction to the performance system for meanings when it appears at LF. As such, the paired features $\left[\mathrm{f}_{\mathrm{P}}, \mathrm{f}_{\mathrm{L}}\right]$ in PL-complexes are naturally bound to be completely split in the course of computation. This means that no extra device or new hypothesis needs to be added to the standard minimalist assumptions in order to capture the synchronization of sounds and meanings. Simply put, Spell-Out 
splits the features on all lexical items into those relevant to PF and those relevant to $\mathrm{LF}$ and separately delivers them to the interfaces, and $\left[\mathrm{FOC}_{\mathrm{P}}\right.$, $\left.\mathrm{FOC}_{\mathrm{L}}\right]$ are only some specific instances of such features.

The core idea of a PL-complex can be traced back at least to the syntactic focus marker "F" proposed by Jackendoff (1972: 240). Jackendoff's "F" and our PF-complexes, however, are distinct in two respects. First, "F" was claimed to be introduced by a syntactic rule in the course of a derivation (in particular, introduced to surface structure by an attachment transformation or to deep structure by a phrase structure rule), reflecting the Extended Standard Theory framework of late 1960s and early 1970s. PLcomplexes, on the other hand, are added directly to lexical items at the outset of a syntactic derivation. Second, "F" is a single feature to be interpreted both phonetically and semantically, while PL-complexes consist of two distinct types of features which are separately interpreted at PF and LF. PL-complexes can be considered the minimalist reincarnation of "F," with the necessary adjustments required by the new theoretical assumptions of minimalism. Such adjustments allow PL-complexes to give us several clear advantages over " $F$ " because they consist of, by definition, two independent features $f_{\mathrm{P}}$ and $f_{\mathrm{L}}$. For instance, when we appeal to this property of PL-complexes, we can reduce cross-linguistic variation in the syntactic realization of $w h$-questions to the variation in the $f_{\mathrm{P}}$ of individual lexical items while maintaining the universality of the paired $f_{\mathrm{L}}$. This point will be discussed in more detail directly below.

An anonymous reviewer questions the value of the proposed approach, claiming that what it achieves is "matched or exceeded by proliferation at the level of Numeration," and hence it falls in the situation described by Chomsky (1981: 13) where he points out that"[s]hifting the variety of devices from one to another component of grammar is no contribution to explanatory adequacy." On the contrary, as pointed out in two preceding paragraphs, an appeal to PL-complexes does not require any extra device or new hypothesis in minimalist syntax. Lexical items are nothing but a bundle of phonological and/or semantic features, to which formal features may be added, and all such features must be properly assorted and sent separately to PF and LF when the computation splits. As described with (45), PL-complexes are added to lexical items just as formal features like Case and F-features are added when the Numeration is formed. Postulating a feature akin to a PL-complex in order to induce both phonetic and semantic effects of focus is not entirely new, as just portrayed above. Finally, as will be argued below, the proposed approach permits us to eliminate theory/ 
model-internal contradictions like look-ahead and look-across problems, which otherwise would remain recalcitrant.

\subsubsection{Interface Licensing}

Up to this point, we have postulated that what starts out as a PL-complex $\left[f_{P}, f_{L}\right]$, i.e. a pair of P-feature and L-feature, comes to be separated in the course of derivation toward PF and toward LF. What is left to be achieved is to identify the role each of these features plays at the interface level. We consider PL-complexes to fulfill the role of guaranteeing that the linguistic expression they are assigned to comes to properly represent a specific linguistic concept (e.g. focus) both at PF and LF. In particular, the PF and the LF for a sentence must represent cues that can eventually be interpreted as appropriate instructions for the relevant performance system. When such interface cues are established, a linguistic expression can be said to become 'legible' at the interface-'physically legible' at PF (henceforth 'P-legible') and 'logically legible' at LF (henceforth 'L-legible'). This way, PL-complexes permit us to maintain the core minimalist tenets (Inclusiveness, Legibility and (Local) Economy) while properly establishing the observed synchronization of sounds and meanings, thus solving the 'look-across' problem.

When we adopt this view of interface licensing, we note that there is a fundamental similarity between the synchronization of 'prosody+semantics' and the synchronization of 'overt movement+semantics.' As such, it is practically useful to use 'overt syntax' to refer to both. We thus use the term overt syntax as a cover term to refer to a grammatical procedure that achieves the synchronized PF- and LF-effects encoded by PLcomplexes. Under this new definition, the synchronization of wh-prosody and $w h$-semantics can be regarded as a product of overt syntax, just as the synchronization of wh-movement and wh-semantics is. Put reversely, overt movement also involves a type of PF-LF synchronization achieved by PLcomplexes. In fact, all of prosody, overt movement, overt morphology, and possibly syntactic location (e.g. adjacency and periphery) can be regarded as properties that have potential to induce P-legibility in overt syntax. This is the motivation for the term 'physical' legibility rather than 'phonetic' legibility. ${ }^{10}$

10 Yoon (2012) and Kitagawa and Yoon (2012) argue that the notions of P- and Llegibility can be made even more general and extended to many other aspects of overt syntax. For instance, they point out that the Visibility Condition (Joseph Aoun, Chom- 


\subsubsection{Overt Syntax with Prosody}

We now examine the overt syntax of $w$ h-questions for which P-legibility is fulfilled by prosody, thus resulting in $w h$-in-situ. This case represents the language types in (34i) and (34iv) (discussed in Section 3.1).

(34i) $\quad[\mathrm{CP} \ldots \mathbf{w h} \ldots \mathbf{C}] \quad$ wh-in-situ Japanese

(34iv) $\quad\left[{ }_{\mathrm{CP}} \mathbf{C} \ldots \mathbf{w h} \ldots\right] \quad w h$-in-situ Chicheŵa

We hypothesize that the notion ' $w h$-focus' is introduced into the Numeration as what we call 'wh-C pair' (cf. Kitagawa and Rodríguez-Mondoñedo (2010), Kitagawa (2011)). A $w h$-C pair is a syntactic unit consisting of a pair of lexical items - a $w h$-word and a Comp $\mathrm{Wh}_{\mathrm{Wh}}$-and specified with a PL-complex of the form $\left[<w h_{P}+C_{P}>,<w h_{L}+C_{L}>\right]$. This is illustrated in (46) below.

(46) Japanese: $<$ nani $+k a / n o>\left(\left[<\mathbf{w h}_{\mathbf{P}}+\mathbf{C}_{\mathbf{P}}>,<\mathbf{w h}_{\mathbf{L}}+\mathbf{C}_{\mathbf{L}}>\right]\right)$

what COMP $_{\mathrm{Wh}}$

Chicheŵa: $<$ chiyáani + kodi $/ \varnothing_{\mathrm{Wh}}>\quad\left(\left[<\mathbf{w h}_{\mathbf{P}}+\mathbf{C}_{\mathbf{P}}>,<\mathbf{w h} \mathbf{h}_{\mathbf{L}}+\mathbf{C}_{\mathbf{L}}>\mathrm{]}\right)\right.$ what COMP $_{\text {Wh }}$

Note that a wh-C pair is 'paired' in two ways - it consists of a pair of lexical items (a $w h$-word and a Comp $\mathrm{wh}_{\mathrm{Wh}}$ ), and it is specified with a PL-complex (the P-features $<w_{P}+C_{P}>$ and the L-features $<w_{L}+C_{L}>$ ). By characterizing a wh-C pair this way, we make the following claim. At the time language users make the 'blueprint' of an utterance by forming a Numeration, they already encode the way $w h$-interrogation is incorporated into that utterance by indicating which item is interpreted as focus and in which projection it takes scope and is interpreted. That is, when a wh-word and its associate complementizer are introduced into the syntax, it is already specified how they must be represented at PF and at LF. The idea of encoding grammatical information as two independent elements that are associated as a single unit is not novel to generative syntax. For instance, in English, perfective aspect, progressive aspect, and the passive construction are often analyzed as one unit consisting of both the auxiliary verb and the verbal inflection (i.e. have $+-E N$, be $+-I N G$ and $b e+-E N$, respectively).

sky (1981: 117)) poses a typical 'look-across' problem in the minimalist framework since it claims to have captured the generalization that Case marking at PF makes an argument NP legible to $\theta$-marking at LF without clarifying how grammar can establish such a correlation. By regarding morphological case, adjacency and periphery as physical implementation of the P-features assigned to a nominal argument as part of a PL-complex, Yoon (2012) and Kitagawa and Yoon (2012) capture such a case- $\theta$ correlation as a synchronized PF-LF effect. 
The P-features $<w_{\mathrm{P}}+\mathrm{C}_{\mathrm{P}}>$ in languages of the type (34i) and (34iv) make the paired $w h$-word and Comp $\mathrm{Wh}_{\mathrm{Wh}}$ become P-legible in the manner described in (47) below.

(47) P-legibility of wh-in-situ:

A $w h$-phrase and a Comp making up a $w h$-C pair become P-legible when their P-features $\left[<\mathbf{w h}_{\mathbf{P}}+\mathbf{C}_{\mathbf{P}}>\right]$ define a unique domain of prosody for focus (henceforth FPd) in such a way that:

(i) $\left[\mathrm{wh}_{\mathrm{P}}\right]$ physically marks the initiation of $\mathrm{FPd}$, and

(ii) the end of the maximal projection headed by $\left[\mathrm{C}_{\mathrm{P}}\right]$ physically marks the termination of FPd.

It is in this way that the PF is realized for cases of $w h$-in-situ, as in (34i) and (34iv). The way FPd is phonetically implemented in such cases, however, varies from language to language (as exemplified in (43) above), though the implementation for any given language is presumably selected from the options made available by Universal Grammar. The most common pattern seems to involve indicating the $w h$-focus word with a distinctively high or low pitch, followed by a stretch of relatively level pitch that terminates at the end of CP (thus marking the end of FPd).

Independently of the licensing at $\mathrm{PF}$, the $w h-C$ pair is made 'L-legible' at LF in the manner described in (48).

(48) L-legibility of a $w h$-question:

A $w h$-phrase and a Comp making up a wh-C pair become L-legible when their $\mathrm{L}$-features $\left[<\mathbf{w h}_{\mathbf{L}}+\mathbf{C}_{\mathrm{L}}>\right]$ define a unique domain of interpretation for focus in such a way that:

(i) $\left[\mathrm{wh}_{\mathrm{L}}\right]$ identifies the item to be interpreted as focus, and

(ii) the maximal projection headed by $\left[\mathrm{C}_{\mathrm{L}}\right]$ is identified as this item's scope domain.

We believe that the L-legibility of wh-questions is established in the same manner (as described in (48)) for both wh-in-situ languages and wh-movement languages. $\left[\mathrm{Wh}_{\mathrm{L}}\right]$ can be considered an interpretable sub-feature that provides $w h$-focus content, while $\left[\mathrm{C}_{\mathrm{L}}\right]$ is an uninterpretable sub-feature that gets deleted when its maximal projection comes to indicate the interpretive domain of focus. We will discuss how L-legibility can be implemented in covert syntax in both $w h$-in-situ and wh-movement languages in Section 3.2.4.3. As for the P-features, $\left[\mathrm{Wh}_{\mathrm{P}}\right]$ in $w h$-in-situ languages can be considered an interpretable sub-feature that provides a phonological tone target that marks the initiation of FPd at PF. In contrast, $\left[\mathrm{C}_{\mathrm{P}}\right]$ is an uninterpre- 
table sub-feature that marks the termination of FPd. ${ }^{11}$ This sub-feature is deleted when it marks the end of the post-focal pitch pattern at the end of the relevant maximal projection. Since $\left[\mathrm{C}_{\mathrm{P}}\right]$ and $\left[\mathrm{C}_{\mathrm{L}}\right]$ of a $w h-\mathrm{C}$ pair are uninterpretable sub-features, their failure to make the wh-C pair visible is expected to induce ungrammaticality. While $\left[\mathrm{wh}_{\mathrm{P}}\right]$ and $\left[\mathrm{wh}_{\mathrm{L}}\right]$ are interpretable sub-features, they must also play a role in making the wh-C pair legible at the interface by being associated with $\left[\mathrm{C}_{\mathrm{P}}\right]$ and $\left[\mathrm{C}_{\mathrm{L}}\right]$, respectively. ${ }^{12}$ Such association will allow the focus prosody starting with a distinctively high or low pitch of a wh-word to be properly terminated, and will also allow the focus value of a wh-word (in the sense of Rooth (1992)) to be elevated to the ordinary semantic value. ${ }^{13}$

How visibility is implemented at PF and LF in a potentially ambiguous wh-question is exemplified for Tokyo Japanese in (49) and (50) and for Fukuoka Japanese in (51) and (52). ${ }^{14}$ Observe how FPd at PF and a $w h$-focus scope domain at LF are aligned in each case when the visibility of the whquestion is established in accordance with (47) and (48). ${ }^{15}$
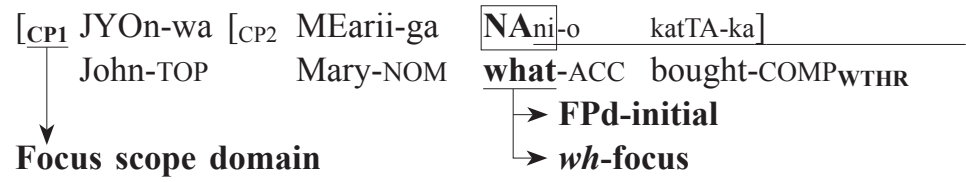

\begin{tabular}{ll} 
Imademo & siRITAGAtteiru-no]? \\
\hline even.now & want.to.know-COMP \\
& FPd-terminal $<$ \\
Head of focus & scope domain $<$
\end{tabular}

(literally) 'What does John still want to learn whether Mary bought?' (=(30))

11 One possible exception is the $\left[\mathrm{C}_{\mathrm{P}}\right]$ that is implemented as a clause-final rising contour in French wh-in-situ.

12 Kitagawa (2005) and Kitagawa and Fodor (2006) argue that native speakers of Japanese unconsciously and implicitly assign wh-prosody even when they process written $w h$ questions in silent reading.

${ }^{13}$ At the same time, the post-focal materials located within FPd at PF presumably come to be regarded as the tail portion of the background of the focus at LF.

14 In Fukuoka Japanese, an accent appears before the subordinate Comp when FPd terminates at the end of the subordinate CP. See Smith (2013) for a discussion on the variations in the prosody-scope correlations exhibited by young Fukuoka Japanese speakers.

${ }^{15}$ While LFs do not have prosodic patterns, prosody is nonetheless indicated in these and the following examples for ease of comparison between PF and LF. 
(50)

$\begin{array}{ll}\text { 50) } & \text { JP1 } \\ & \text { John-Top } \\ \text { PF: } & \\ \text { LF: } & \text { Focus scope domain }\end{array}$

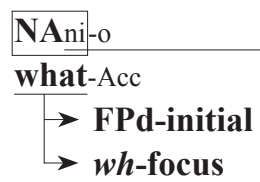

$$
\begin{aligned}
& \begin{array}{lll}
\text { katTA-ka }] & \text { Imademo } & \text { siRITAGAtteiru-no]? } \\
\hline \text { bought-Compwh2 } & \text { even.now } & \text { want.to.know-CompY/N }
\end{array} \\
& \rightarrow \text { FPd-terminal } \\
& \rightarrow \text { Head of focus scope domain }
\end{aligned}
$$

'Does John still want to learn what Mary bought?' (=(31))

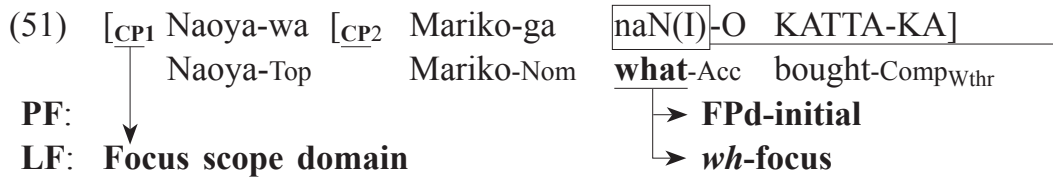

\begin{tabular}{r} 
WAKARAN-TO] \\
\hline not.know-Compwh1 \\
FPd-terminal 4 \\
Head of focus scope domain 4
\end{tabular}

(literally) 'What does Naoya not know whether Mariko bought?'
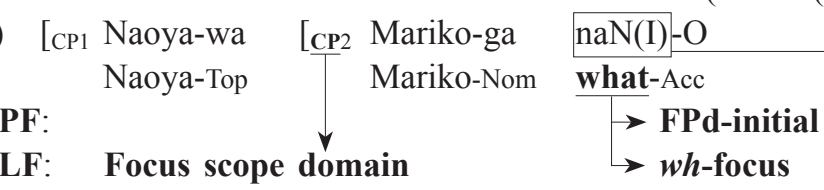

$(52)$

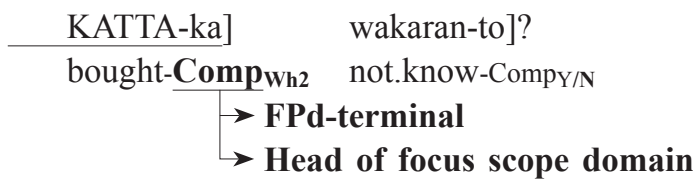

'Does Naoya not know what Mariko bought?'

(Smith (2013: 119))

In head-final languages like Japanese, FPd is terminated at Comp $p_{W h}$. Since this Comp $\mathrm{Wh}_{\mathrm{W}}$ is the head of the scope domain of the $w h$-focus word, the marking of the end of FPd at PF is even more clearly linked to the interpretive domain of the $w h$-focus at LF in Japanese than it is in Comp-initial wh- 
in-situ languages like Chicheŵa exemplified in (53).

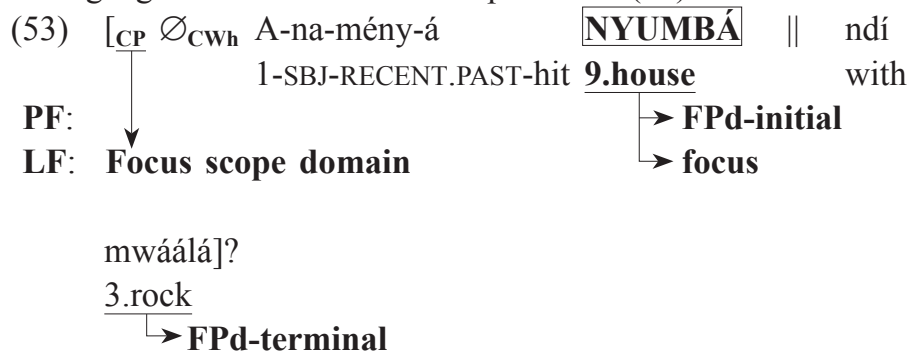

'S/he hit the HOUSE with a rock.'

Note that FPd as a whole at PF (e.g. what $\sim$ Comp $_{W h 1}$ in (49)) does not necessarily correspond to the focus scope domain at LF (e.g. $\mathrm{CP}_{1}$ in (49)). Instead, the two are merely linked, with the endpoint of $\mathrm{CP}_{1}$ functioning as their pivot. In this way, the proposed approach captures the prosody-interpretation synchronization between the unsynchronized PF and LF domains in $w h$-in-situ languages.

As we saw in Section 3.1, French permits two distinct types of FPd, which are illustrated in (54a) and (54b) below. (54a) involves a compressed pitch on the wh-word and an utterance-final rise (indicated by $\uparrow$ ), whereas (54b) involves clearly elevated pitch on the $w h$-word followed by a sequence of low pitch.

$$
\begin{array}{r}
\text { a. } \mathbf{P F}_{1}:\left[{ }_{\mathrm{CP}} \varnothing_{\text {CompWh }} \begin{array}{l}
\text { Elle a mis } \\
\text { she has placed élément au }
\end{array}\right. \\
\text { milieu } \uparrow] \text { ? } \\
\text { middle } \\
\text { FPd-terminal } 4
\end{array}
$$

b. $\mathbf{P F}_{2}:\left[{ }_{\mathrm{CP}} \varnothing_{\mathrm{CompWh}}\right.$ Elle a mis QUELÉLÉMENT she has placed which shape $\rightarrow$ FPd-initial

au milieu]?
in.the middle
FPd-terminal $<$

Both PFs in (54) can be paired with the LF in (55) below, whose L-legibility is achieved in accordance with (48). 


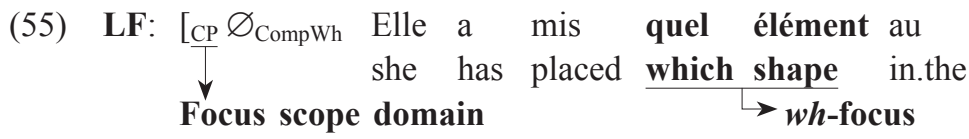

milieu]?

middle

(literally) 'She placed which shape in the middle?'

To sum up so far, we can induce the synchronization of prosody and whinterpretation observed in $w$ h-in-situ languages by introducing a ' $w$ h-C pair' characterized by a PL-complex $\left[<\mathrm{wh}_{\mathrm{P}}+\mathrm{C}_{\mathrm{P}}>,<\mathrm{wh}_{\mathrm{L}}+\mathrm{C}_{\mathrm{L}}>\right]$ into syntax at the outset of the derivation. This PL-complex then becomes separated when the syntactic derivation splits toward $\mathrm{PF}$ and LF. At the respective interfaces, $<w h_{P}+C_{P}>$ and $<w h_{L}+C_{L}>$ are properly interpreted, thus making the linguistic expressions associated with them 'legible.' This approach effectively solves the 'look-across' problem of the prosody-semantics correlations pointed out in Section 3.2.2 above.

\subsubsection{Overt Syntax with Displacement}

We now examine the overt syntax of $w h$-questions in which P-legibility is fulfilled by displacement of the phonetic content of a wh-phrase (i.e., fulfilled by overt wh-movement). In this case, the (presumably uninterpretable) P-features $<w_{P}+C_{P}>$ make the associated linguistic expressions P-legible in the manner described in (56) below. This gives rise to the language type in (34iii).

(56) P-legibility of wh-movement:

A wh-phrase and a Comp making up a wh-C pair become Plegible when their P-features $\left.\left[<\mathbf{w h}_{\mathbf{P}}+\mathbf{C}_{\mathbf{P}}\right\rangle\right]$ initiate a unique $\mathrm{CP}$ in such a way that $\left[\mathrm{wh}_{\mathrm{P}}\right]$ is located at the left periphery of the maximal projection of $\left[\mathrm{C}_{\mathrm{P}}\right]$.

(34iii) $\left[\begin{array}{llll}\mathrm{CP} & \mathbf{C} & \ldots & \mathbf{w h}\end{array} \ldots\right] \quad$ wh-move to left $\quad$ English/Tagalog

As stated above, we assume that the L-legibility of a $w h$-question is established uniformly as in (48), whether it involves wh-in-situ or wh-movement. Thus, the visibility of $w h$-movement in English is implemented at both $\mathrm{PF}$ and LF, as exemplified in (57).

(57) $\left[\mathrm{CP1}\right.$ I don't know $\left[\mathrm{CP2}\right.$ what $\mathbf{C}_{2}$ she bought what $\left.\left.{ }_{4}\right]\right]$

PF:

LF: Focus scope domain $\longrightarrow$ wh-focus 
3.2.4.3. Structural Conditions on the Implementation of L-legibility

It seems clear that L-legibility in wh-in-situ languages must be implemented in covert syntax by appealing to the relative syntactic relation between the $w h$-word and the maximal projection of its associated Comp $\mathrm{Wh}_{\mathrm{Wh}}$. The examples we have examined thus far, e.g. (49) and (50), verify that both matrix $\mathrm{CP}\left(\mathrm{CP}_{\mathrm{M}}\right)$ and subordinate $\mathrm{CP}\left(\mathrm{CP}_{\mathrm{S}}\right)$ can serve as the scope domain of the subordinate $w h$-in-situ $\left(\mathrm{Wh}_{\mathrm{S}}\right)$ in a construction schematized in (58).

(58)

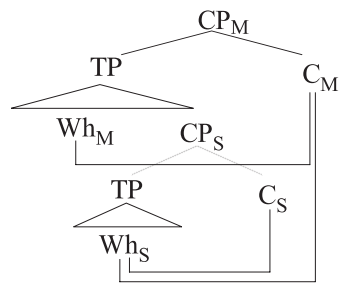

As is well-known, however, only $\mathrm{CP}_{\mathrm{M}}$ can serve as the scope domain for the matrix $w h$-in-situ $\left(\mathrm{Wh}_{\mathrm{M}}\right)$. The L-legibility of a $w h$-C pair in Japanese (and possibly all $w h$-in-situ languages) thus seems to be implemented in logical syntax under the structural condition as in (59).

(59) $\left[\mathrm{Wh}_{\mathrm{L}}\right]$ is dominated by the maximal projection of $\left[\mathrm{C}_{\mathrm{L}}\right]$.

In $w$-movement languages, on the other hand, L-legibility of a wh-C pair is implemented under the structural condition as in (60).

(60) $\left[\mathrm{Wh}_{\mathrm{L}}\right]$ is located directly under the maximal projection of $\left[\mathrm{C}_{\mathrm{L}}\right]$.

One possible way to assimilate the two cases is to treat (60) as an effect that holds for not just wh-movement languages but also for wh-in-situ languages. Wh-movement would then have to take place in covert syntax to achieve L-legibility as in (60) and derive an LF as in (61).

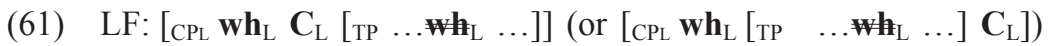
Since we have hypothesized that a $w h$-C pair (as a unit) represents a $w h$ focus construction, it might be reasonable to consider that a hierarchicallylocal union of the $w h$-word and Comp $\mathrm{Wh}_{\mathrm{Wh}}$ at LF is a universal requirement. Here, we consider $\left[\mathrm{C}_{\mathrm{L}}\right]$ to be an uninterpretable feature that gets deleted when the union of the $w h$-word and Comp $p_{W h}$ is achieved and the interpretive domain of $w h$-focus is identified at LF. Alternatively, we may hypothesize that the L-legibility of a $w h$-C pair in $w h$-movement languages is also implemented as in (59) but involves the 'tail copy' $\left[\mathrm{Wh}_{\mathrm{L}}\right]$ within $\mathrm{TP}$ to be interpreted as a choice function variable (cf. Reinhart (1997)). We must, however, leave further pursuit of this topic to future research. 


\subsubsection{Overt Syntax Revisited}

Let us now return to the 'look-ahead' problem of overt movement pointed out in Section 3.2.1. The 'P/L-legibility' analysis of overt whmovement sketched out above may be regarded advocating the view that overt wh-movement is a PF-movement that also induces synchronized LFeffects. This analysis effectively solves the look-ahead problem in question since physical (and hence overt) dislocation of phonetic content now takes place in the course of the derivation toward PF, and its application is motivated strictly by an interface requirement. While this approach can stand as a perfectly self-contained proposal, we can in fact take a step further and bring overt movement back into syntax with only small revisions of the minimalist model of grammar. The fact that the current minimalist model of grammar cannot achieve overt movement without inducing a look-ahead problem suggests, in itself, a need to redesign the model.

Let us therefore explore the alternative remodeling of the computational component of the minimalist grammar illustrated in (62).

(62) Suggested Remodeling of Minimalist Grammar:

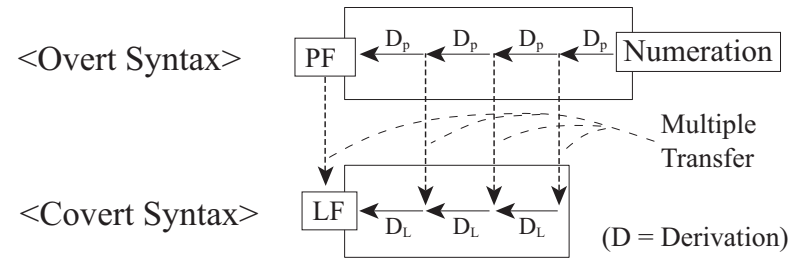

The crucial revision here is that overt syntax and covert syntax do not overlap. They are completely separate and operate in the following order. Overt syntax starts with the generation of linguistic expressions by (externally) merging the features encoded in lexical items and their projections. The goal of overt syntax is to derive a well-formed PF, at which the P-legibility of linguistic expressions must be achieved. An operation in overt syntax is enacted solely for this purpose, triggered by the $f_{\mathrm{P}}$ of a PL-complex. For example, a $\left[W h_{\mathrm{P}}\right]$ sub-feature assigned to a $w h$-word in English requires that word's maximal projection to keep moving to the periphery of a syntactic object each time merge applies. This process continues until it eventually reaches the left periphery of the CP headed by its associated Comp containing $\left[C_{\mathrm{P}}\right]$. This way, overt $w h$-movement applies in overt syntax without inducing any look-ahead problem(, which is inevitably caused by EPP characterized as 'I need a Spec' (Bošković (2007)). In a nutshell, overt syntax determines the overt/physical properties of syntactic expressions that are relevant to $\mathrm{PF}$, such as the domain of prosodic/phonetic 
activities (e.g. FPd domain) and the linear and hierarchical order of the phonetic content of syntactic elements (e.g. displacement).

At any derivational stage of overt syntax, any portion of the logical and semantico-pragmatic properties of lexical items (L-features) may be extracted away from P-features and fed into covert syntax 'as needed' for interpretation. This is achieved by multiple transfer, applying in the way proposed by Epstein et al. (1998). Such a 'derivational' interpretation can induce, for instance, various LF-reconstruction effects.

This way, the overt syntactic operations in (62) may induce synchronized semantic effects, but this is due to the design of grammar, not because its application within overt syntax is triggered by LF factors. Covert syntax then attempts to derive a well-formed LF, at which L-legibility of linguistic expressions must be achieved. In short, covert syntax determines only the properties of syntactic expressions that are relevant to LF, such as the hierarchical relations and dependencies among syntactic constituents (e.g. the predicate-argument relation, the operator-variable relation and its scope). ${ }^{16}$

While the proposed reorganization of syntax may appear to be drastic at first sight, the revisions are in fact relatively small-scale. First, this reorganization has simply decomposed traditional overt syntax by untangling and separating its PF-effects and LF-effects, while permitting them to be synchronized with an appeal to PL-complexes. Second, multiple transfer merely applies in the opposite way to Spell-Out, stripping away L-features rather than P-features from the feature complexes of lexical items. If such small-scale revisions permit us to account for the synchronization of sounds and meanings while avoiding the serious theoretical problems involving 'look-ahead' and 'look-across,' it is certainly worth exploring them, although their full evaluation will require much future research. ${ }^{17}$

${ }^{16}$ Here, we are assuming, rather loosely, that the overt syntactic derivation is subject to the rules of phonology and phonetics toward its end before it derives PF, and covert syntactic derivation is subject to semantics toward its end before it derives LF. To be more precise, (62) should be regarded as a model of two syntactic components whose output representations are subject to further derivation in phonology/phonetics and semantics, respectively.

17 It should be made clear that (62) is proposed as a model of grammar, not as an acquisition model. 


\section{REFERENCES}

Arregi, Karlos (2002) Focus on Basque Movements, Doctoral dissertation, MIT.

Bayssade, Claire, Elisabeth Delais-Roussarie and Jean-Marie Marandin (2007) "The Prosody of Interrogatives in French," Nouveaux Cahiers de Linguistique Fançaise 28, 163-175.

Bošković, Željko (2007) "On the Locality and Motivation of Move and Agree: An Even More Minimal Theory," Linguistic Inquiry 38, 589-644.

Cecchetto, Carlo, Carlo Geraci and Sandro Zucchi (2009) "Another Way to Mark Syntactic Dependencies: The Case for Right-Peripheral Specifiers in Sign Languages," Language 85, 278-320.

Cheng, Lisa Lai-Shen and Johan Rooryk (2000) "Licensing Wh-in-situ," Syntax 3, $1-19$.

Chomsky, Noam (1981) Lectures on Government and Binding, Foris, Dordrecht.

Chomsky, Noam (2000) "Minimalist Inquiries: the Framework," Step by Step: Essays on Minimalist Syntax in Honor of Howard Lasnik, ed. by Roger Martin, David Michaels and Juan Uriagereka, 89-155, MIT Press, Cambridge, MA.

Chomsky, Noam (2001) "Derivation by Phase," Ken Hale: A Life in Language, ed. by Michael Kenstowicz, 1-52, MIT Press, Cambridge, MA.

Deguchi, Masanori and Yoshihisa Kitagawa (2002) "Prosody and Wh-questions," Proceedings of the Thirty-second Annual Meeting of the North-Eastern Linguistic Society, 73-92.

Déprez, Viviane, Kristen Syrett and Shigeto Kawahara (2013) "The Interaction of Syntax, Prosody, and Discourse in Licensing French Wh-in-situ Questions," Lingua 124 Special Issue Prosody at the Grammatical Crossroads: Japanese and Beyond, 4-19.

Downing, Laura J. (2005) "The Prosody of Focus-Related Enclitics in Some Southern Bantu Languages," Handout from talk given at SOAS.

Downing, Laura J. (2011) "Wh-Questions in Chewa and Tumbuka: Positions and Prosodies," Questions in Bantu Languages: Prosodies and Positions, ZAS Papers in Linguistics 55, 23-46.

Downing, Laura J., Al Mtenje and Bernd Pompino-Marschall (2004) "Prosody and Information Structure in Chichewa," ZAS Papers in Linguistics 37, 167-186.

Downing, Laura J. and Bernd Pompino-Marschall (2013) "The Focus Prosody of Chichewa and the Stress-Focus Constraint: A Response to Samek-Lodovici (2005)," Natural Language and Linguistic Theory Online First Article, 1-35.

Elordieta, Gorka (1997) "Accent, Tone and Intonation in Lekeitio Basque," Issues in the Phonology and Morphology of the Major Iberian Languages, ed. by Fernando Martinez-Gil and Alfonso Morales-Front, Georgetown University Press, Washingon, D.C.

Embick, David and Rolf Noyer (2001) "Movement Operations after Syntax," Linguistic Inquiry 32, 555-595.

Epstein, Samuel David, Erich M. Groat, Ruriko Kawashima and Hisatsugu Kitahara (1998) A Derivational Approach to Syntactic Relations, Oxford University Press, 
New York.

Halle, Morris and Alec Marantz (1993) "Distributed Morphology and the Pieces of Inflection," The View from Building 20: Essays in Linguistics in Honor of Sylvain Bromberger, ed. by Kenneth Hale and Samuel Jay Keyser, 111-176, MIT Press, Cambridge, MA.

Ishihara, Shinichiro (2003) Intonation and Interface Conditions, Doctoral dissertation, MIT.

Ishihara, Shinichiro (2011) "Japanese Focus Prosody Revisited: Freeing Focus from Prosodic Phrasing,” Lingua 121, 1870-1889.

Jackendoff, Ray (1972) Semantic Interpretation in Generative Grammar, MIT Press, Cambridge, MA.

Kanerva, Jonni (1989) Focus and Phrasing in Chicheŵ tation, Stanford University.

Kayne, Richard (1994) The Antisymmetry of Syntax, MIT Press, Cambridge, MA.

Kitagawa, Yoshihisa (2005) "Prosody, Syntax and Pragmatics of Wh-questions in Japanese," English Linguistics 22, 302-346.

Kitagawa, Yoshihisa (2011) "Decomposing Overt Syntax," Japanese/Korean Linguistics $19,61-80$.

Kitagawa, Yoshihisa and Janet Dean Fodor (2006) "Prosodic Influences on Syntactic Judgments," Gradience in Grammar: Generative Perspectives, ed. by Gisbert Fanselow, Caroline Fery, Matthias Schlesewsky and Ralf Vogel, 336-358, Oxford University Press, Oxford.

Kitagawa, Yoshihisa and Miguel Rodríguez-Mondoñedo (2010) "When Syntax Must Become Overt," paper presented at New Horizons in the Minimalist Program: SyntaxFest 2010, Indiana Univerisity.

Kitagawa, Yoshihisa and Junghyoe Yoon (2012) "Case Reincarnated," paper presented at the Seventh International Workshop on Theoretical East Asian Linguistics.

Kubo, Tomoyuki (1989) "Fukuokashi Hoogen no Dare, Nanitoono Gimonshi o Fukumu Bunno Pitti Pataan (The Pitch Patterns of Sentences Containing the Interrogatives such as Who/What in the Fukuoka-City Dialect)," Kokugo-gaku $156,71-82$.

Kuno, Susumu (1982) "The Focus of the Question and the Focus of the Answer," Papers from the Parasession on Nondeclaratives, CLS, 134-157.

Ladd, Robert (1996) Intonational Phonology, Cambridge University Press, Cambridge.

Lasnik, Howard (2011) "Multiple Sluicing in English?” ms., University of Maryland.

Maekawa, Kikuo (1991) "Perception of Intonation Characteristics of WH and nonWH Questions in Tokyo Japanese," Proceedings of the XXIInd International Congress of Phonetic Science 4, 202-205.

Maekawa, Kikuo (1994) "Is There 'Dephrasing' of the Accentual Phrase in Japanese?” OSU Working Papers in Linguistics 44, 146-165.

Myers, Scott (1996) "Boundary Tones and the Phonetic Implementation of Tone in Chichewa," Studies in African Linguistics 25, 29-60.

Nissenbaum, Jon (2000) Investigations of Covert Phrase Movement, Doctoral disser- 
tation, MIT.

Pesetsky, David (1998) "Some Optimality Principles of Sentence Pronunciation," Is the Best Good Enough?: Optimality and Competition in Syntax, ed. by Martha Barbosa, Danny Fox, Paul Hagstrom, Martha McGinnis and David Pesetsky, 337-383, MIT Press, Cambridge, MA.

Pierrehumbert, Janet and Mary Beckman (1988) Japanese Tone Structure, MIT Press, Cambridge, MA.

Reinhart, Tanya (1997) "Quantifier Scope: How Labor is Divided between QR and Choice Functions," Linguistics and Philosophy 20, 335-397.

Richards, Norvin (2010) Uttering Trees, MIT Press, Cambridge, MA.

Rizzi, Luigi (1997) "The Fine Structrure of the Left Periphery," Elements of Grammar: Handbook in Generative Syntax, ed. by Liliane Haegeman, 281-337, Kluwer, Dordrecht.

Rooth, Mats (1992) “A Theory of Focus Interpretation," Natural Language Semantics $1,75-116$.

Selkirk, Elisabeth and Koichi Tateishi (1988) "Constraints on Minor Phrase Formation in Japanese," Papers from the Twenty-fourth Regional Meeting of the Chicago Linguistic Society, 316-336.

Selkirk, Elisabeth and Koichi Tateishi (1991) "Syntax and Downstep in Japanese," Interdisciplinary Approaches to Language: Essays in Honor of S.-Y. Kuroda, ed. by Carol Georgopoulos and Roberta Ishihara, 519-543, Kluwer, Dordrecht.

Shinya, Takahito, Elisabeth Selkirk and Shigeto Kawahara (2004) "Rhythmic Boost and Recursive Minor Phrase in Japanese," Proceedings of the Second International Conference on Speech Prosody, 183-186.

Smith, Jennifer L. (2005) "On the WH-Question Intonational Domain in Fukuoka Japanese: Some Implications for the Syntax-Prosody Interface," Papers on Prosody, UMOP, ed. by Shigeto Kawahara, 219-237, GLSA, Amherst, MA.

Smith, Jennifer L. (2013) "Fukuoka Japanese Wh Prosody in Production and Perception," Lingua 124 Special Issue Prosody at the Grammatical Crossroads: Japanese and Beyond, 96-130.

Truckenbrodt, Hubert (1999) "On the Relation between Syntactic Phrases and Phonological Phrases," Linguistic Inquiry 30, 219-255.

Wachowicz, Krystyna (1978) "Q-morpheme Hypothesis, Performative Analysis and an Alternative," Questions, ed. by Henry Hiz, 151-164, Reidel, Dordrecht.

Yoon, Junghyoe (2012) Case Drop in Korean-Its Empirical and Theoretical Investigation, Doctoral dissertation, Indiana University.

[received October 3 2012, revised and accepted January 31 2013] 
Department of Linguistics

Memorial Hall 325

Indiana University

Bloomington, IN 47405-7005

U.S.A.

e-mail: kitagawa@indiana.edu 